\title{
Copper activates HIF-1a/GPER/VEGF signalling in cancer cells
}

\author{
Damiano Cosimo Rigiracciolo ${ }^{1}$, Andrea Scarpelli ${ }^{1}$, Rosamaria Lappano ${ }^{1}$, Assunta \\ Pisano ${ }^{1}$, Maria Francesca Santolla ${ }^{1}$, Paola De Marco ${ }^{1}$, Francesca Cirillo ${ }^{1}$, Anna Rita \\ Cappello $^{1}$, Vincenza Dolce ${ }^{1}$, Antonino Belfiore ${ }^{2}$, Marcello Maggiolini ${ }^{1}$ and Ernestina \\ Marianna De Francesco ${ }^{1}$ \\ ${ }^{1}$ Department of Pharmacy, Health and Nutritional Sciences, University of Calabria, Rende, Italy \\ 2 Endocrinology, Department of Health, University Magna Graecia of Catanzaro, Catanzaro, Italy \\ Correspondence to: Marcello Maggiolini, email: marcellomaggiolini@yahoo.it \\ Keywords: copper, cancer, angiogenesis, GPER, HIF-1a, VEGF, Pathology Section \\ Received: June 15,2015 Accepted: August 31, $2015 \quad$ Published: September 22, 2015
}

This is an open-access article distributed under the terms of the Creative Commons Attribution License, which permits unrestricted use, distribution, and reproduction in any medium, provided the original author and source are credited.

\section{ABSTRACT}

Copper promotes tumor angiogenesis, nevertheless the mechanisms involved remain to be fully understood. We have recently demonstrated that the G-protein estrogen receptor (GPER) cooperates with hypoxia inducible factor-1a (HIF-1a) toward the regulation of the pro-angiogenic factor VEGF. Here, we show that copper sulfate $\left(\mathrm{CuSO}_{4}\right)$ induces the expression of HIF-1a as well as GPER and VEGF in breast and hepatic cancer cells through the activation of the EGFR/ERK/c-fos transduction pathway. Worthy, the copper chelating agent TEPA and the ROS scavenger NAC prevented the aforementioned stimulatory effects. We also ascertained that HIF-1a and GPER are required for the transcriptional activation of VEGF induced by $\mathrm{CuSO}_{4}$. In addition, in human endothelial cells, the conditioned medium from breast cancer cells treated with $\mathrm{CuSO}_{4}$ promoted cell migration and tube formation through HIF-1a and GPER.

The present results provide novel insights into the molecular mechanisms involved by copper in triggering angiogenesis and tumor progression. Our data broaden the therapeutic potential of copper chelating agents against tumor angiogenesis and progression.

\section{INTRODUCTION}

Copper, which is an essential trace element naturally occurring in soil, water and air, acts as a catalytic and/or structural cofactor in a wide array of important biological processes like embryogenesis, growth, homeostasis and angiogenesis $[1,2]$. An elevated exposure to copper may be mainly consequent to environmental pollution from the manufacture of wire, sheet metal, pipe and other metal products [2]. In addition, mining, waste dumps, combustion of fossil fuels, wood production and phosphate fertilizers release copper in the environment, thus contributing to the actual exposure in humans [2-4]. To date, mismanaged or high copper levels have been involved in the generation of oxidative stress [5] which plays an important role in cancer development [6]. In this regard, it should be mentioned that physiological concentrations of copper range approximately from
18 to $31 \mu \mathrm{M}$ [7], while serum copper levels have been found in cancer patients from $50 \mu \mathrm{M}$ to $205 \mu \mathrm{M}$ or even at $\mathrm{mM}$ concentrations [8-10]. Of note, elevated copper concentrations were correlated with cancer stage and/or progression in diverse types of tumors, thus suggesting that copper may be a useful prognostic factor and a marker of responsiveness to therapy [reviewed in 8]. On the basis of these findings, a number of studies investigated the stimulatory action of copper on VEGF production and tumor angiogenesis [11-13] and the repressive effects exerted by copper-chelating on HIF- $1 \alpha$ mediated expression of VEGF $[14,15]$.

Numerous G-protein coupled receptors (GPCRs) contribute to the angiogenic switch through mechanisms that include their functional interaction with HIF-1 $\alpha$ toward VEGF expression [16]. In this regard, our recent study has shown that the $G$ protein estrogen receptor (GPER) cooperates with HIF-1 $\alpha$ in order to modulate 
VEGF in hypoxic breast tumor microenvironment [17]. In addition, we have demonstrated that estrogenic GPER signalling activates HIF-1 $\alpha$ /VEGF transduction pathway leading to angiogenesis and tumor growth [18].

Here, we provide novel evidence on the mechanisms by which copper triggers the EGFR/ERK/c-fos signalling cascade along with GPER and HIF-1 $\alpha$ toward VEGF expression and function in cancer cells. We also show that GPER may be considered as an additional target of copper chelating agents, hence broadening the therapeutic potential of these chemicals against tumor angiogenesis and progression.

\section{RESULTS}

\section{$\mathrm{CuSO}_{4}$ induces the expression of the pro- angiogenic factor VEGF}

Considering that copper and its chelating agents have been involved in tumor angiogenesis [5], we asked whether copper sulfate $\left(\mathrm{CuSO}_{4}\right)$ may induce the expression of the pro-angiogenic factor VEGF and its transcriptional regulator $\mathrm{HIF}-1 \alpha$ in $\mathrm{SkBr} 3$ breast cancer cells and HepG2 hepatocellular carcinoma cells. Of note, $\mathrm{CuSO}_{4}$ induced the mRNA expression of both HIF-1 $\alpha$ (Figure 1A) and VEGF (Figure 1B) in a dose dependent manner, starting from $25 \mu \mathrm{M}$ and reaching the strongest stimulation upon concentrations ranging from 100 to 200 $\mu \mathrm{M}$. Taking into account these results and considering that in previous studies relevant biological responses to copper exposure were observed up to $500 \mu \mathrm{M}$ [19-21], in the subsequent assays of the current study $200 \mu \mathrm{M} \mathrm{CuSO}_{4}$ were used. First, we determined that $\mathrm{CuSO}_{4}$ up-regulates in a time-dependent manner the mRNA expression of HIF-1 $\alpha$ (Figure 1C) and VEGF (Figure 1D) in $\mathrm{SkBr} 3$ and HepG2 cells. Thereafter, we ascertained that the well-acknowledged copper chelating agent TEPA [14, 22] as well as the extensively used ROS scavenger NAC [reviewed in 23] prevent the mRNA induction of HIF-1 $\alpha$ (Figure 1E) and VEGF (Figure 1F) and the transactivation of a VEGF promoter construct (Figure 1G) upon treatment with $\mathrm{CuSO}_{4}$. As copper has been previously involved in HIF- $1 \alpha$ responses to low oxygen conditions $[14,15]$, we then assessed the effect of TEPA on the action of the hypoxia-mimetic agent $\mathrm{CoCl}_{2}$. As expected, $\mathrm{CoCl}_{2}$ induced the mRNA expression of HIF-1 $\alpha$ (Figure 2A) and VEGF (Figure 2B) as well as the transactivation of a VEGF promoter construct (Figure 2C) in $\mathrm{SkBr} 3$ and HepG2 cells. Interestingly, these effects were abolished in the presence of TEPA and rescued adding $\mathrm{CuSO}_{4}$ to $\mathrm{SkBr} 3$ and $\mathrm{HepG} 2$ cells (Figure 2). Results similar to those observed using $\mathrm{CoCl}_{2}$ were obtained culturing $\mathrm{SkBr} 3$ and HepG2 cells in a low oxygen tension $\left(2 \% \mathrm{O}_{2}\right)$ (Supplementary Figure $1 \mathrm{~A}$ 1C).
Collectively, these findings suggest that $\mathrm{CuSO}_{4}$ may be involved in the activation of HIF-1 $\alpha /$ VEGF transduction signalling in cancer cells. On the basis of our recent findings suggesting that a functional crosstalk between HIF-1 $\alpha$ and GPER may occur toward the VEGF expression in hypoxic conditions [24, 17-18], we next determined that the up-regulation of GPER mRNA expression induced by $\mathrm{CuSO}_{4}$ in $\mathrm{SkBr} 3$ and HepG2 cells (Figure 3A, 3B) is abolished in the presence of both TEPA and NAC (Figure 3C). Moreover, the transactivation of a GPER promoter construct triggered by $\mathrm{CuSO}_{4}$ was prevented using TEPA and NAC (Figure 3D). Notably, the GPER mRNA induction and the GPER promoter transactivation induced by $\mathrm{CoCl}_{2}$ were prevented in the presence of TEPA and rescued adding $\mathrm{CuSO}_{4}$ (Figure 3E, 3F). Results comparable to those observed upon $\mathrm{CoCl}_{2}$ treatment were obtained culturing cells in a low oxygen tension $\left(2 \% \mathrm{O}_{2}\right)$ (Supplementary Figure 1D-1E). Cumulatively, these data recall previous studies showing that the inhibitory effects of TEPA on hypoxia-induced responses are rescued by $\mathrm{CuSO}_{4}$ in a dose-dependent manner [14].

Altogether, these data indicate that GPER may be included among the transduction mediators triggered by copper, in particular in stressful conditions characterized by a low oxygen tension in cancer cells.

\section{Molecular mechanisms involved in the stimulatory actions elicited by $\mathrm{CuSO}_{4}$}

As c-fos expression is a molecular sensor of both GPER and HIF-1 $\alpha$ signalling [18, 25-26], we also demonstrated that c-fos mRNA increase upon $\mathrm{CuSO}_{4}$ stimulation (Figure $3 \mathrm{G}, 3 \mathrm{H}$ ) is abrogated in the presence of TEPA and NAC (Figure 3I). Nicely fitting with these results, the transactivation of a c-fos luciferase construct and AP1-luc promoter sequence induced by $\mathrm{CuSO}_{4}$ was repressed in the presence of TEPA and NAC (Figure 3J). Recapitulating the aforementioned findings, the protein induction of c-fos, HIF-1 $\alpha$ and GPER observed upon $\mathrm{CuSO}_{4}$ treatment was abrogated in the presence of TEPA and NAC in $\mathrm{SkBr} 3$ and HepG2 cells (Figure 4A-4D). Given that the activation of EGFR/ERK signalling triggers transduction mechanisms leading to gene expression changes as mentioned above [17-18, 25, 27-28], we ascertained that the EGFR and ERK1/2 phosphorylation induced by $\mathrm{CuSO}_{4}$ in both $\mathrm{SkBr} 3$ and HepG2 cells (Figure $5 \mathrm{~A}, 5 \mathrm{~B})$ is blocked in the presence of the EGFR tyrosine kinase inhibitor AG1478 (AG) and the MEK inhibitor PD98059 (PD) (Figure 5C, 5D) as well as using TEPA and NAC (Figure 5E, 5F). Further corroborating these data, the up-regulation of c-fos, HIF-1 $\alpha$, GPER and VEGF mRNA expression (Figure 6A-6D) as well as the transactivation of fos-luc, AP1-luc, GPER-luc and VEGFluc reporter constructs (Figure 6E, 6F) induced by $\mathrm{CuSO}_{4}$ 
A

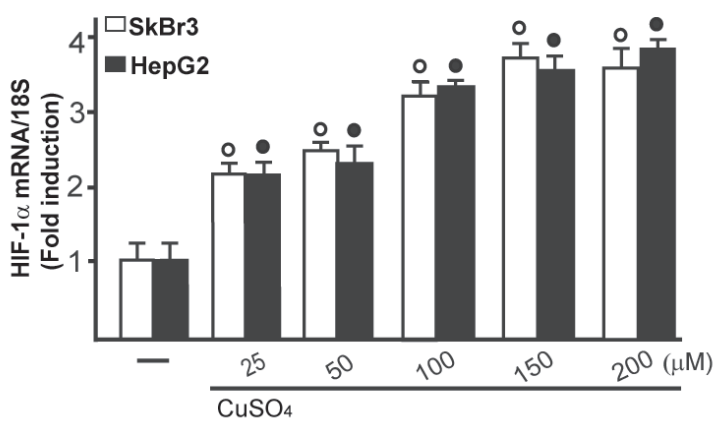

C

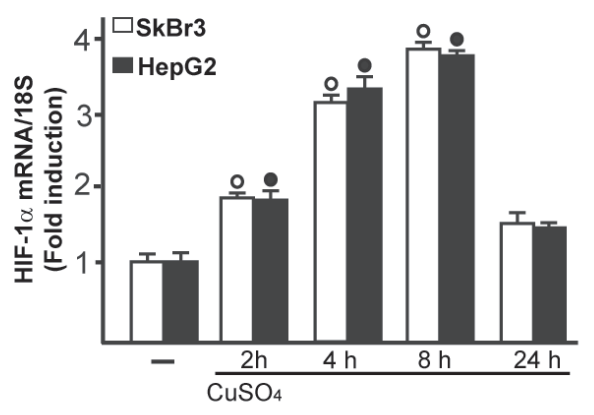

E

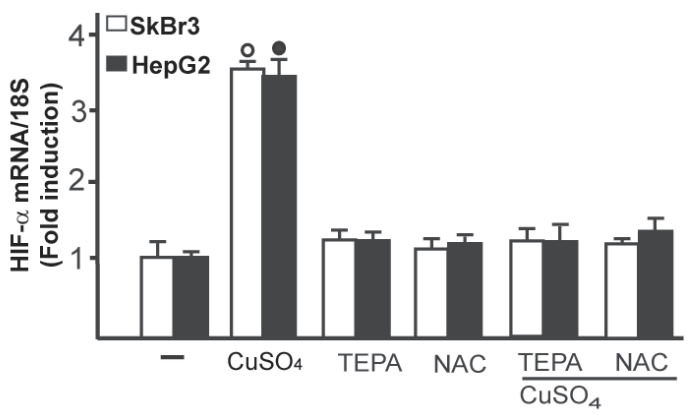

G

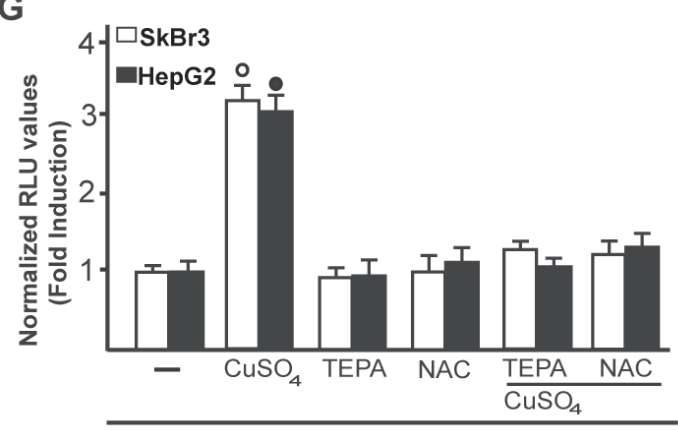

B

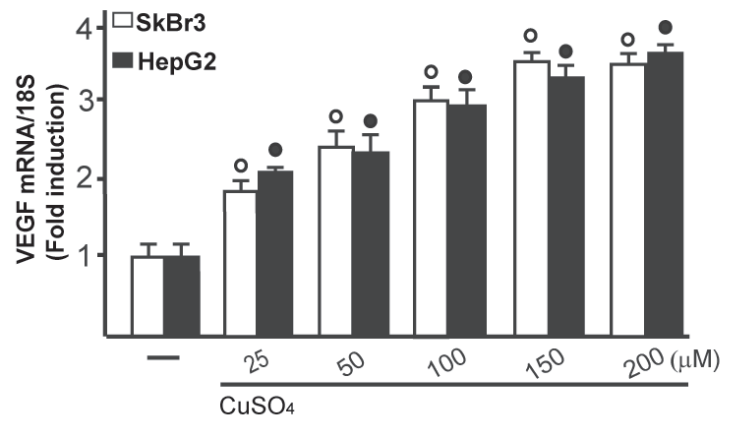

D

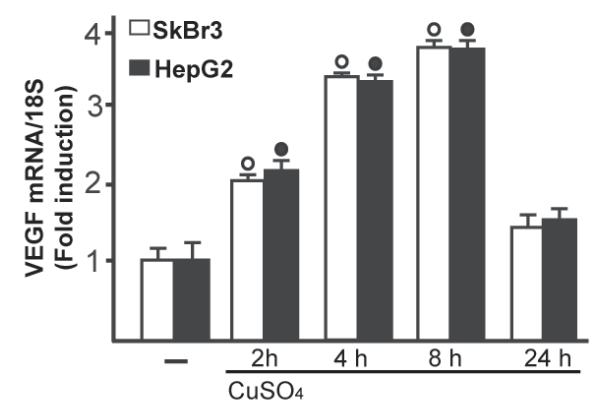

$\mathbf{F}$

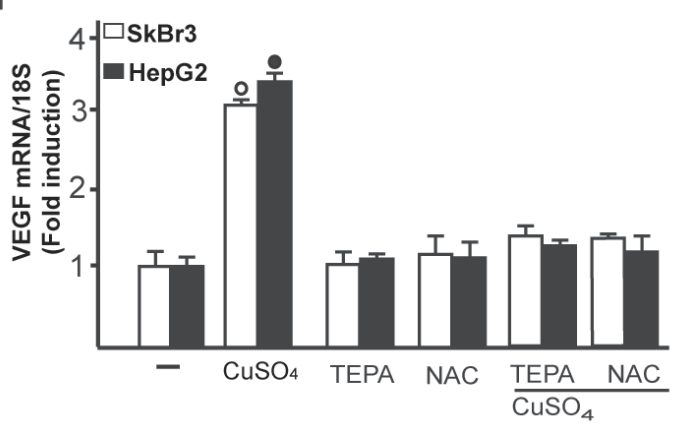

Figure 1: $\mathrm{CuSO}_{4}$ induces the mRNA expression of HIF-1 $\alpha$ and VEGF. mRNA expression of HIF-1 $\alpha$ A. and VEGF B. in SkBr3 and $\mathrm{HepG} 2$ cells treated with increasing concentrations of $\mathrm{CuSO}_{4}$ for 8 hours, as evaluated by real-time PCR. $\mathrm{CuSO}_{4}(200 \mu \mathrm{M})$ induces the mRNA expression of HIF- $1 \alpha \mathbf{C}$. and VEGF D. in a time-dependent manner. In SkBr3 and HepG2 cells treated with $200 \mu \mathrm{M} \mathrm{CuSO}_{4}$ for 8 hours, the mRNA induction of HIF-1 $\alpha \mathbf{E}$. and VEGF F. is abrogated in the presence of the copper chelating agent TEPA $(50 \mu \mathrm{M})$ and the ROS scavenger NAC $(300 \mu \mathrm{M})$. Values are normalized to the $18 \mathrm{~S}$ expression and shown as fold changes of the mRNA expression induced by $\mathrm{CuSO}_{4}$ compared to cells treated with vehicle (-). G. The transactivation of a VEGF promoter plasmid (pVEGF) observed in $\mathrm{SkBr} 3$ and HepG2 cells treated with $200 \mu \mathrm{M} \mathrm{CuSO}_{4}$ for 12 hours is prevented by TEPA $(50 \mu \mathrm{M})$ and NAC $(300 \mu \mathrm{M})$. The luciferase activities were normalized to the internal transfection control and values of cells receiving vehicle (-) were set as 1 -fold induction upon which the activities induced by $\mathrm{CuSO}_{4}$ treatment were calculated. Each data point represents the mean $\pm \mathrm{SD}$ of three independent experiments performed in triplicate. (०), $(\bullet) p<0.05$ for cells receiving vehicle (-) versus $\mathrm{CuSO}_{4}$ treatment. 
were abolished in the presence of AG and PD. Analogous findings were obtained evaluating the regulation of c-fos, HIF- $1 \alpha$ and GPER protein expression in $\mathrm{SkBr} 3$ and HepG2 cells (Figure 6G, 6H).

Immunofluorescence experiments performed in $\mathrm{SkBr} 3$ cells showed that TEPA, NAC, AG and PD prevent also the increase of VEGF protein expression upon $\mathrm{CuSO}_{4}$ treatment (Figure 7). In addition, the HIF$1 \alpha$ protein increase triggered by $\mathrm{CuSO}_{4}$ was no longer evident transfecting $\mathrm{SkBr} 3$ and $\mathrm{HepG} 2$ cells with a plasmid encoding a dominant/negative c-fos mutant (DN/c-fos) (Figure 8A, 8B). In accordance with the aforementioned results, the up-regulation of GPER (Figure 8A, 8B) and VEGF (Figure 8C, 8D) protein levels upon $\mathrm{CuSO}_{4}$ treatment was prevented by $\mathrm{DN} / \mathrm{c}-\mathrm{fos}$, as evaluated by immunoblotting and immunofluorescence assays, respectively. As demonstrated in our previous investigations, in hypoxic tumor microenvironment HIF$1 \alpha$ mediates the expression of GPER that contributes to the regulation and function of VEGF $[17,24]$. Likewise, we found that the GPER protein up-regulation induced by $\mathrm{CuSO}_{4}$ as well as the transactivation of the GPER promoter were abolished knocking down HIF-1 $\alpha$ expression (Figure 9A-9F). In addition, the silencing of $\mathrm{HIF}-1 \alpha$ prevented the $\mathrm{CuSO}_{4}$-induced activation of the VEGF promoter construct (Figure 9G, 9H) as well as the up-regulation of VEGF protein expression (Figure 9I-9K). Of note, GPER was required for VEGF protein induction
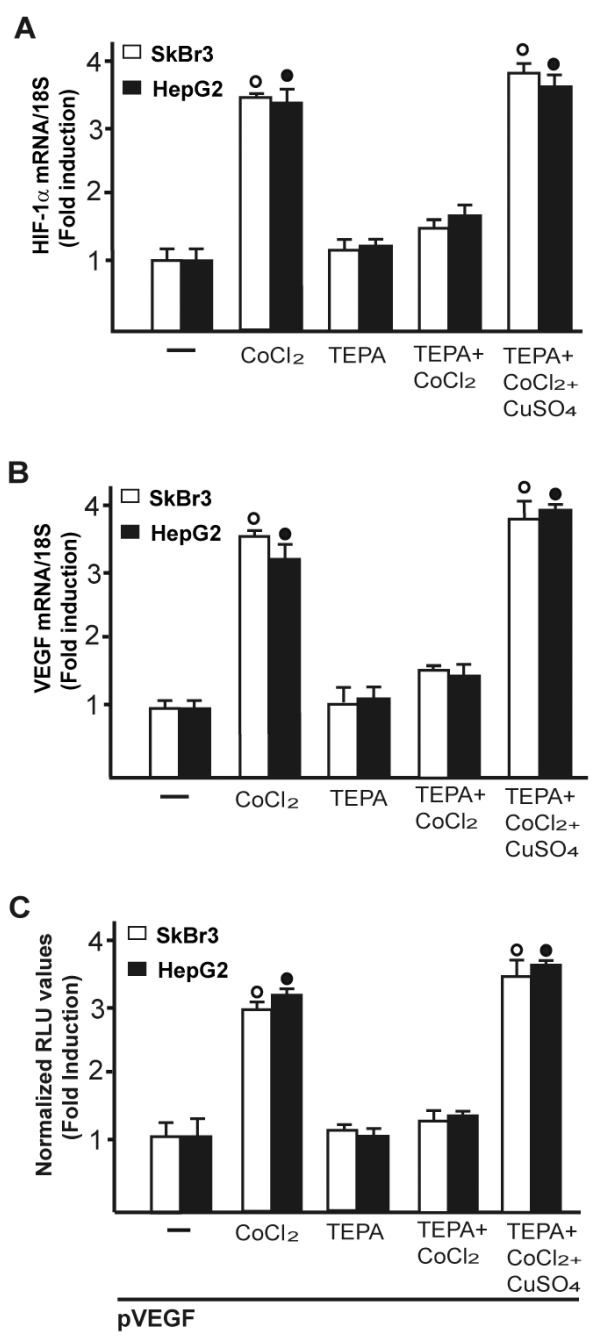

Figure 2: $\mathrm{CuSO}_{4}$ rescues the inhibitory effects of TEPA on $\mathrm{CoCl}_{2}$-induced transcription of $\mathrm{HIF}-1 \alpha$ and $\mathrm{VEGF}$. In SkBr3 and HepG2 cells, the up-regulation of HIF-1 $\alpha$ A. and VEGF B. mRNA expression induced upon $\mathrm{CoCl}_{2}$ treatment (100 $\mu \mathrm{M}$ for 8 hours) is no longer evident in the presence of TEPA $(50 \mu \mathrm{M})$ but rescued using $\mathrm{CoCl}_{2}(100 \mu \mathrm{M}$ for 8 hours $)$ in combination with $200 \mu \mathrm{M} \mathrm{CuSO}$, as determined by real-time PCR. Values are normalized to the $18 \mathrm{~S}$ expression and shown as fold changes of mRNA expression induced by treatments respect to cells treated with vehicle (-). C. The transactivation of a VEGF promoter plasmid (pVEGF) observed in SkBr3 and HepG2 cells treated with $100 \mu \mathrm{M} \mathrm{CoCl}_{2}$ for 12 hours is prevented by TEPA $(50 \mu \mathrm{M})$ and rescued using $\mathrm{CoCl}_{2}(100 \mu \mathrm{M}$ for 12 hours) in combination with $200 \mu \mathrm{M} \mathrm{CuSO}_{4}$. The luciferase activities were normalized to the internal transfection control and values of cells receiving vehicle (-) were set as 1 -fold induction upon which the activities induced by $\mathrm{CoCl}_{2}$ treatment were calculated. Each data point represents

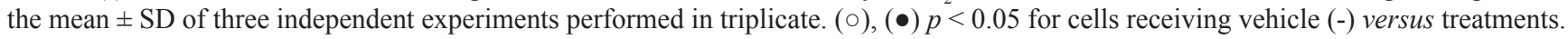


A
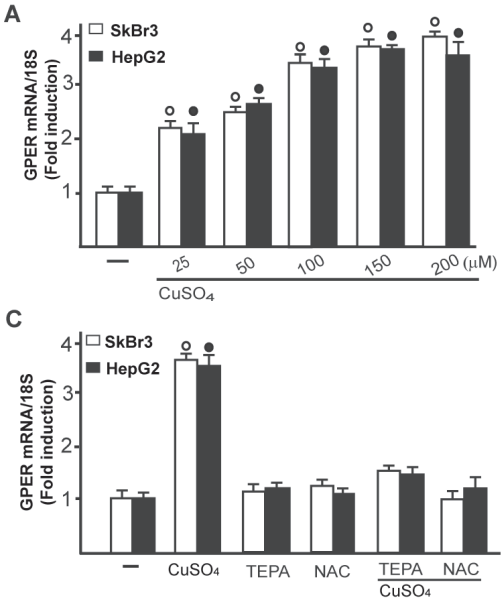

E

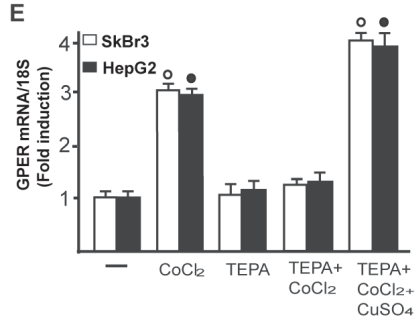

G
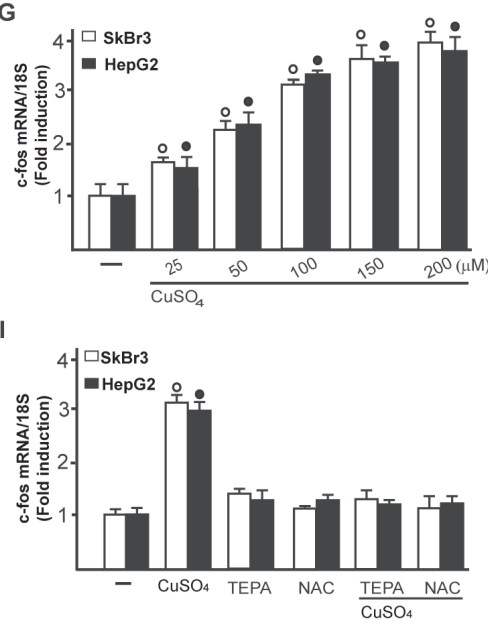

B

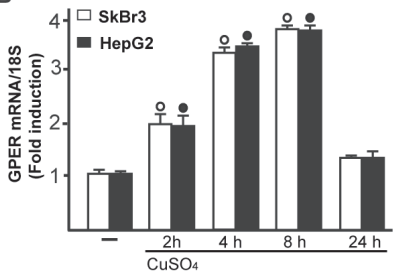

D

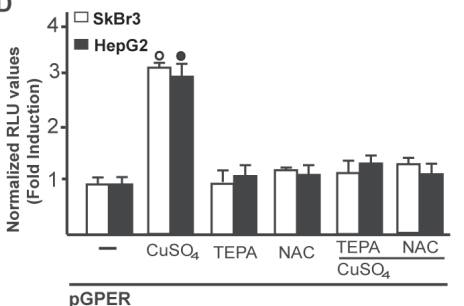

F

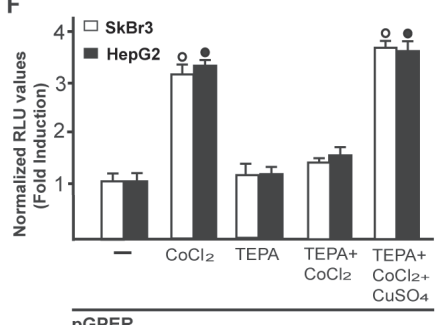

H

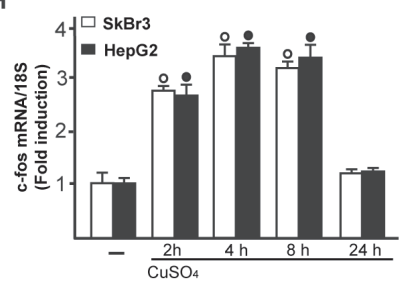

J

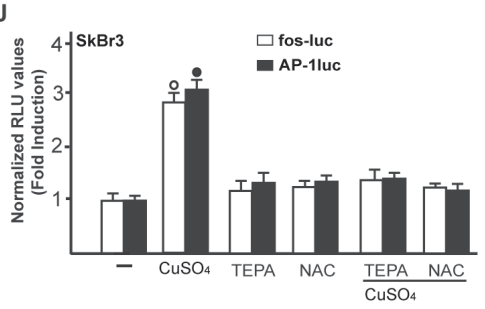

Figure 3: $\mathrm{CuSO}_{4}$ induces the mRNA expression of GPER. mRNA expression of GPER in $\mathrm{SkBr} 3$ and HepG2 cells treated with increasing concentrations of $\mathrm{CuSO}_{4}$ for 8 hours, as evaluated by real-time PCR A. $\mathrm{CuSO}_{4}(200 \mu \mathrm{M})$ induces the mRNA expression of GPER in a time-dependent manner B. The increase in GPER mRNA observed treating SkBr3 and HepG2 cells for 8 hours with $200 \mu \mathrm{M}$ $\mathrm{CuSO}_{4}$ is abrogated in the presence of TEPA $(50 \mu \mathrm{M})$ and NAC $(300 \mu \mathrm{M}) \mathbf{C}$. The transactivation of a GPER promoter plasmid (pGPER) observed in SkBr3 and HepG2 cells treated with $200 \mu \mathrm{M} \mathrm{CuSO}_{4}$ for 12 hours is prevented by TEPA $(50 \mu \mathrm{M})$ and NAC (300 $\left.\mu \mathrm{M}\right) \mathbf{D}$. The mRNA induction of GPER observed in SkBr3 and HepG2 cells treated with $100 \mu \mathrm{M} \mathrm{CoCl}_{2}$ for 8 hours is abrogated in the presence of TEPA $(50 \mu \mathrm{M})$ and rescued using $\mathrm{CoCl}_{2}(100 \mu \mathrm{M}$ for 8 hours $)$ in combination with $200 \mu \mathrm{M} \mathrm{CuSO}_{4}$, as determined by real-time PCR E. The transactivation of a GPER promoter plasmid (pGPER) observed in $\mathrm{SkBr} 3$ and HepG2 cells treated with $100 \mu \mathrm{M} \mathrm{CoCl}_{2}$ for 12 hours is prevented by TEPA $(50 \mu \mathrm{M})$ and rescued using $\mathrm{CoCl}_{2}\left(100 \mu \mathrm{M}\right.$ for 12 hours) in combination with $200 \mu \mathrm{M}_{\text {CuSO}}$ F. Dose-response increase of c-fos mRNA expression in $\mathrm{SkBr} 3$ and $\mathrm{HepG} 2$ cells treated with $\mathrm{CuSO}_{4}$ for 8 hours, as evaluated by real-time PCR $\mathbf{~ G}$. CuSO $(200 \mu \mathrm{M})$ induces the mRNA expression of $\mathbf{c}-$ fos in a time-dependent manner $\mathbf{H}$. The mRNA increase of c-fos observed treating SkBr3 and HepG2 cells for 8 hours with $200 \mu \mathrm{M} \mathrm{CuSO}_{4}$ is abrogated in the presence of TEPA $(50 \mu \mathrm{M})$ and NAC $(300 \mu \mathrm{M})$ I. The transactivation of c-fos (fos-luc) and AP-1 (AP-1luc) reporter plasmids observed in $\mathrm{SkBr} 3$ cells treated with $200 \mu \mathrm{M} \mathrm{CuSO}_{4}$ for 12 hours is prevented by TEPA $(50 \mu \mathrm{M})$ and NAC $(300 \mu \mathrm{M}) \mathbf{J}$. In transfection assays, the luciferase activities were normalized to the internal transfection control and values of cells receiving vehicle (-) were set as 1-fold induction upon which the activities induced by treatments were calculated. In RNA experiments, values are normalized to the $18 \mathrm{~S}$ expression and shown as fold changes of mRNA expression induced by treatments compared to cells treated with vehicle (-). Each data point represents the mean \pm SD of three independent experiments performed in triplicate. $(\circ),(\bullet)$ $p<0.05$ for cells receiving vehicle (-) versus treatments. 
and the transactivation of a VEGF promoter construct by $\mathrm{CuSO}_{4}$, as demonstrated by silencing experiments (Figure 10A-10E). Overall, these data highlight the transduction mechanisms involved by copper toward the stimulation of VEGF in cancer cells.
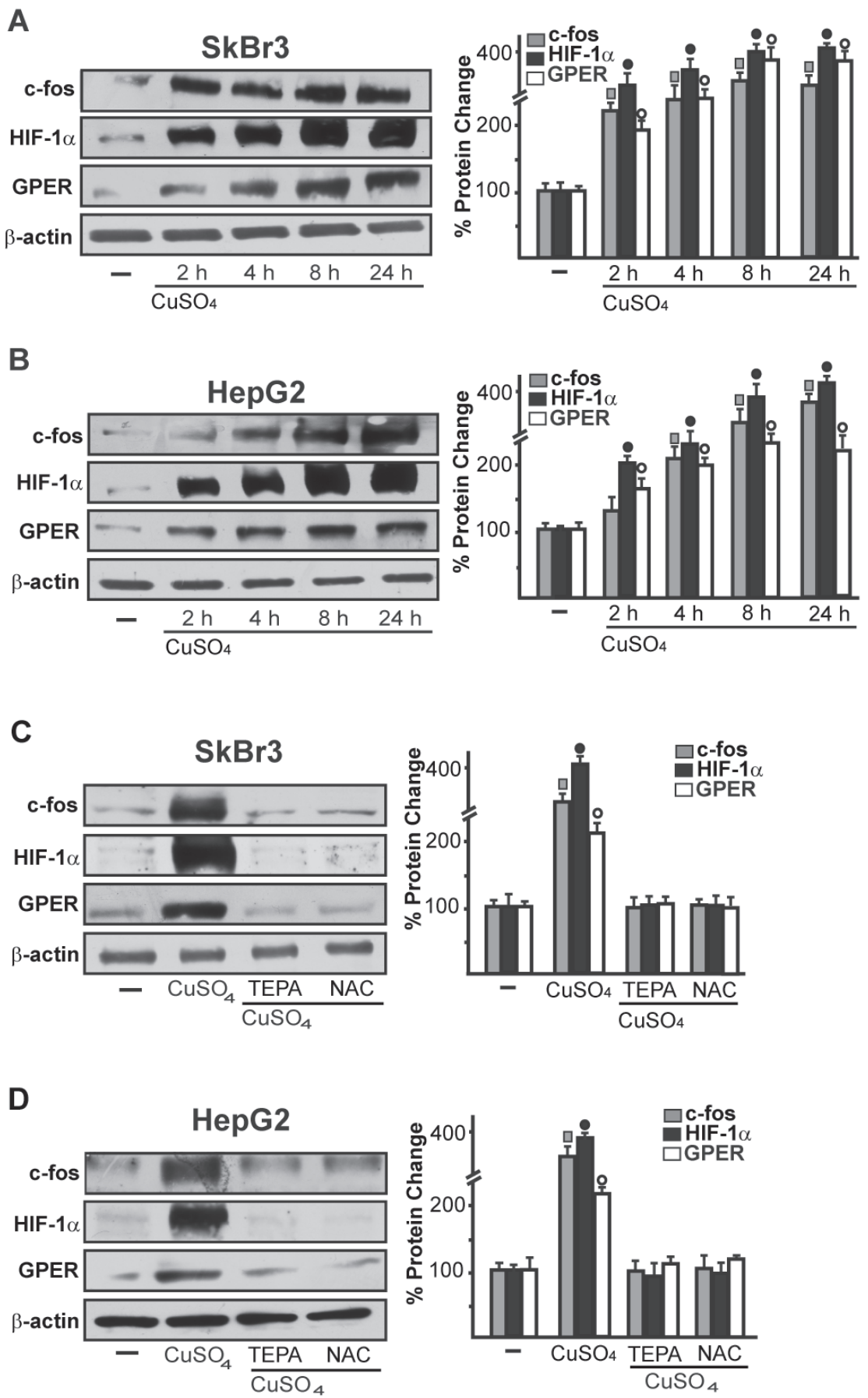

Figure 4: $\mathrm{CuSO}_{4}$ induces the protein expression of c-fos, HIF-1 $\alpha$ and GPER. Up-regulation of c-fos, HIF-1 $\alpha$ and GPER protein expression in $\mathrm{SkBr} 3$ and $\mathrm{HepG} 2$ cells treated with $200 \mu \mathrm{M} \mathrm{CuSO}_{4}$ for 8 hours A., B. The induction of c-fos, HIF-1 $\alpha$ and GPER protein expression observed upon treatment with $200 \mu \mathrm{M} \mathrm{CuSO}_{4}$ for 8 hours is abolished in the presence of TEPA (50 $\left.\mu \mathrm{M}\right)$ and NAC $(300 \mu \mathrm{M})$ C., D. Results shown are representative of three independent experiments. Side panels show densitometric analysis of the blots normalized to $\beta$-actin. $(\square),(\bullet),(\circ), p<0.05$ for cells receiving vehicle (-) versus $\mathrm{CuSO}_{4}$ treatment. 
$\mathrm{CuSO}_{4}$, we assessed in HUVECs the involvement of HIF$1 \alpha$ and GPER in the formation of tubule-like structures that represent a useful experimental model of angiogenic process [29]. Interestingly, a ramified network of tubules was generated in HUVECs cultured in conditioned medium from $\mathrm{CuSO}_{4}$-treated $\mathrm{SkBr} 3$ cells (Figure 11A). However this effect was prevented by knocking down the expression of HIF-1 $\alpha$ or GPER (Figure 11B-11H). The addition of VEGF to the medium collected from $\mathrm{CuSO}_{4}$-treated and GPER-silenced $\mathrm{SkBr} 3$ cells rescued the generation of tubule structures in HUVECs (Figure 11C). Figure 11 (panels D-F) recapitulates these results, suggesting that VEGF may be considered as a target of copper-activated HIF-1 $\alpha /$ GPER signalling toward new blood vessels formation. As in previous studies VEGF boosted endothelial cells migration [30-31] we then evaluated whether HIF- $1 \alpha$ and GPER are involved in the migration of HUVECs. Conditioned medium from $\mathrm{SkBr} 3$ cells exposed to $\mathrm{CuSO}_{4}$ induced the migration of HUVECs (Figure 12A), however this response was abrogated silencing HIF-1 $\alpha$ and GPER expression (Figure 12B-12E). Indeed, the addition of VEGF rescued cell migration culturing HUVECs in medium collected from SkBr3 cells which were GPER-silenced and treated with $\mathrm{CuSO}_{4}$ (Figure 12C). Next, we determined that HIF-1 $\alpha$ and GPER are required for $\mathrm{SkBr} 3$ cell proliferation induced by $\mathrm{CuSO}_{4}$, as this response was prevented knocking-down their expression (Supplementary Figure S2A-C). Likewise, the growth effects elicited by $\mathrm{CuSO}_{4}$ was abolished in the presence of TEPA (Supplementary Figure S2D). Altogether, these findings suggest that copper may trigger relevant biological actions through HIF-1 $\alpha /$ GPER/VEGF transduction signalling in both cancer and endothelial cells toward angiogenesis and tumor progression.

\section{DISCUSSION}

The present study provides novel evidence regarding the molecular mechanisms by which copper may trigger the expression and function of VEGF toward angiogenesis and tumor progression. In particular, we have shown that copper activates the EGFR/ERK/c-fos transduction pathway leading to the expression of HIF-1 $\alpha$, GPER and VEGF in breast and hepatic cancer cells. In this regard,
A

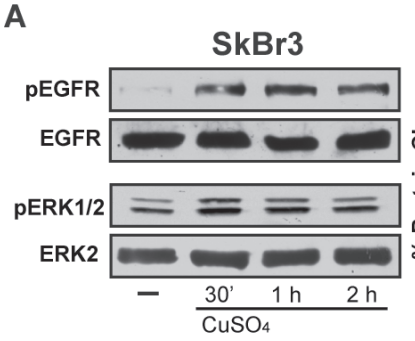

C

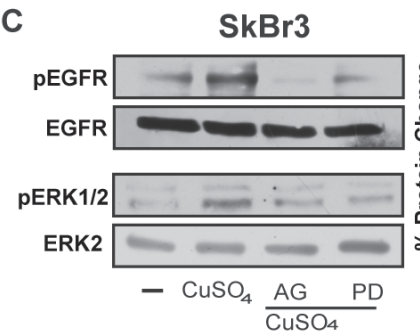

$\mathbf{E}$

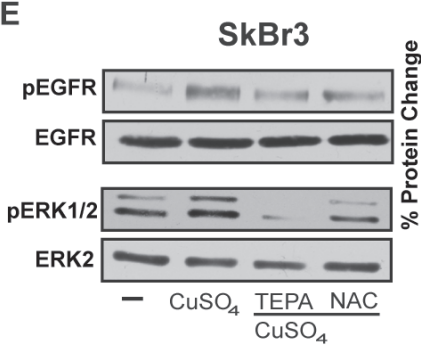

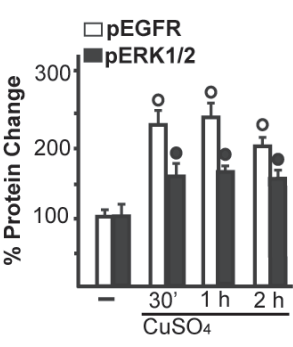

B
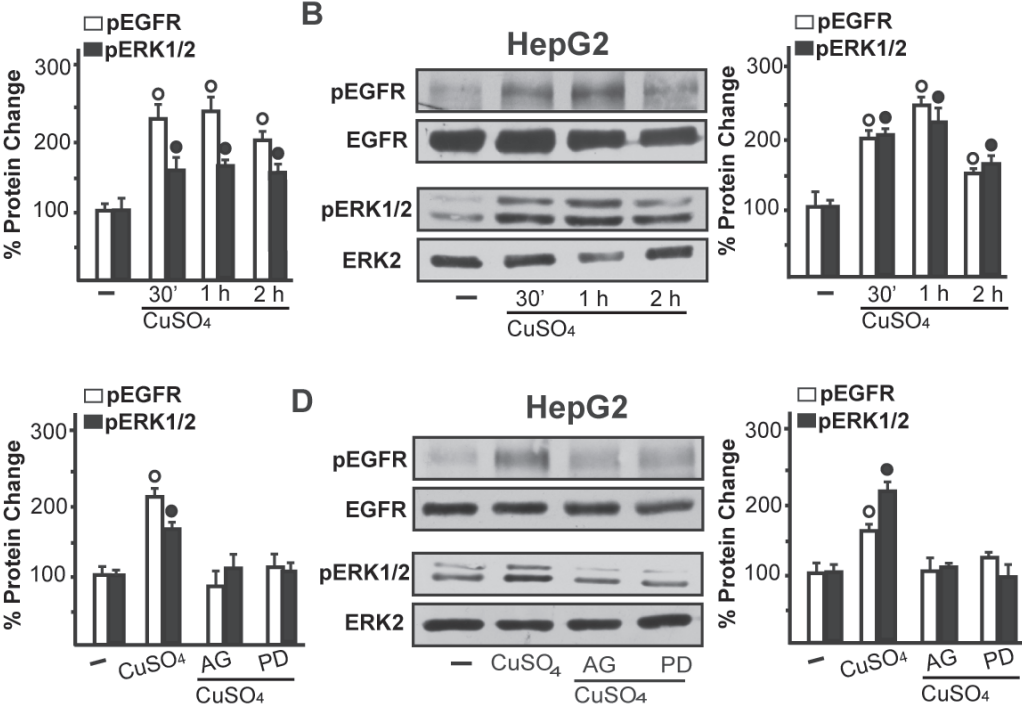

D
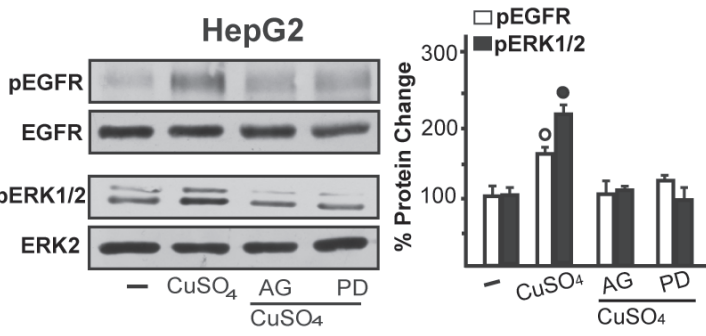

$\mathbf{F}$

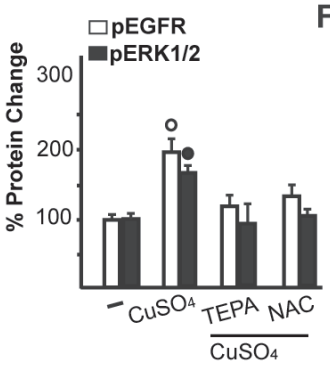

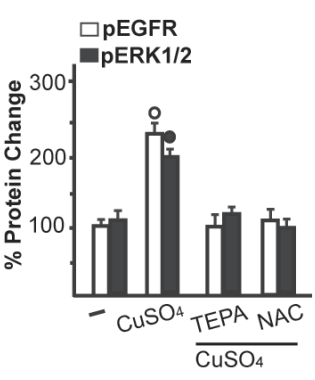

Figure 5: $\mathrm{CuSO}_{4}$ induces EGFR and ERK activation. The exposure to $200 \mu \mathrm{M} \mathrm{CuSO}_{4}$ induces EGFR (Tyr 1173$)$ and ERK1/2 phosphorylation in SkBr3 and HepG2 cells A., B. The activation of EGFR and ERK1/2 observed in SkBr3 and HepG2 cells treated with $200 \mu \mathrm{M} \mathrm{CuSO}_{4}$ for $30 \mathrm{~min}$ is abrogated in the presence of the EGFR inhibitor AG1478 (AG, $\left.10 \mu \mathrm{M}\right)$ and the MEK inhibitor PD98059 $(\mathrm{PD}, 10 \mu \mathrm{M})$ C., D. as well as TEPA $(50 \mu \mathrm{M})$ and NAC $(300 \mu \mathrm{M})$ E., F. Side panels show densitometric analysis of the blots normalized to EGFR or ERK2. Each data point represents the mean \pm SD of three independent experiments. (०), (•) $p<0.05$ for cells receiving vehicle (-) versus $\mathrm{CuSO}_{4}$ treatment. 

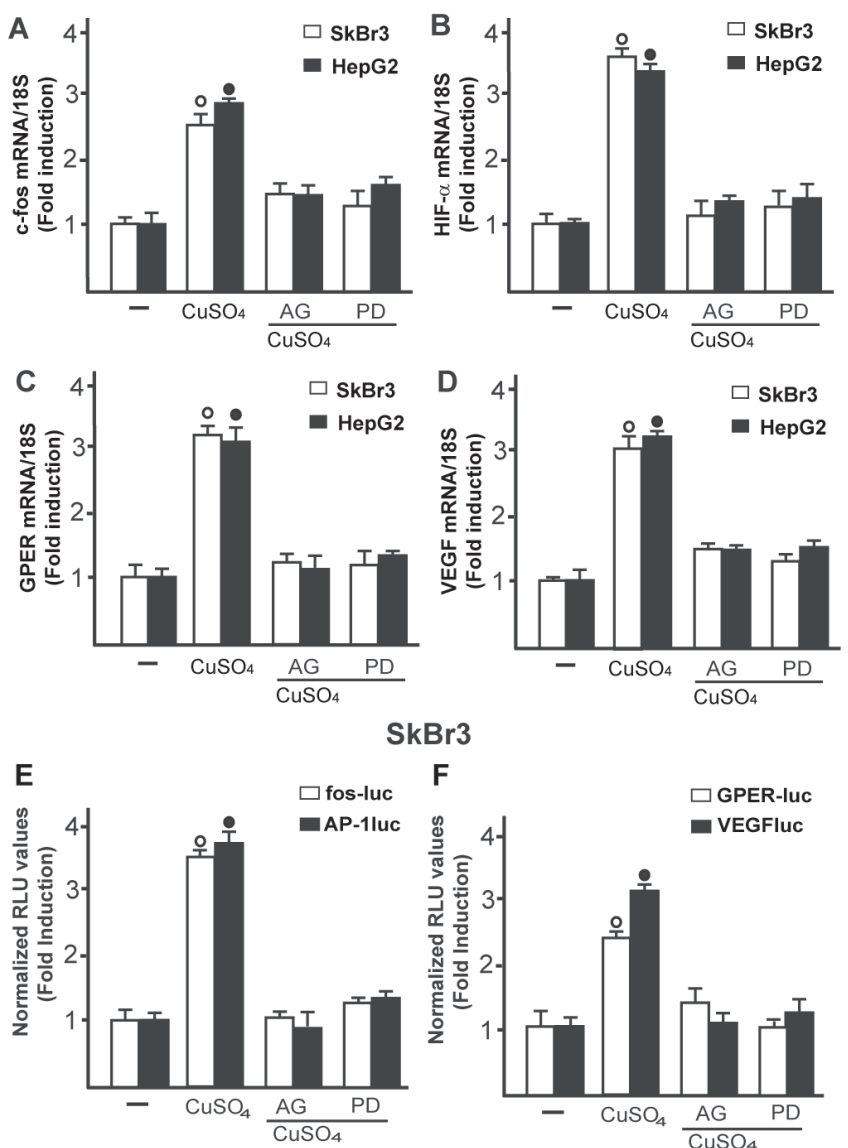

SkBr3
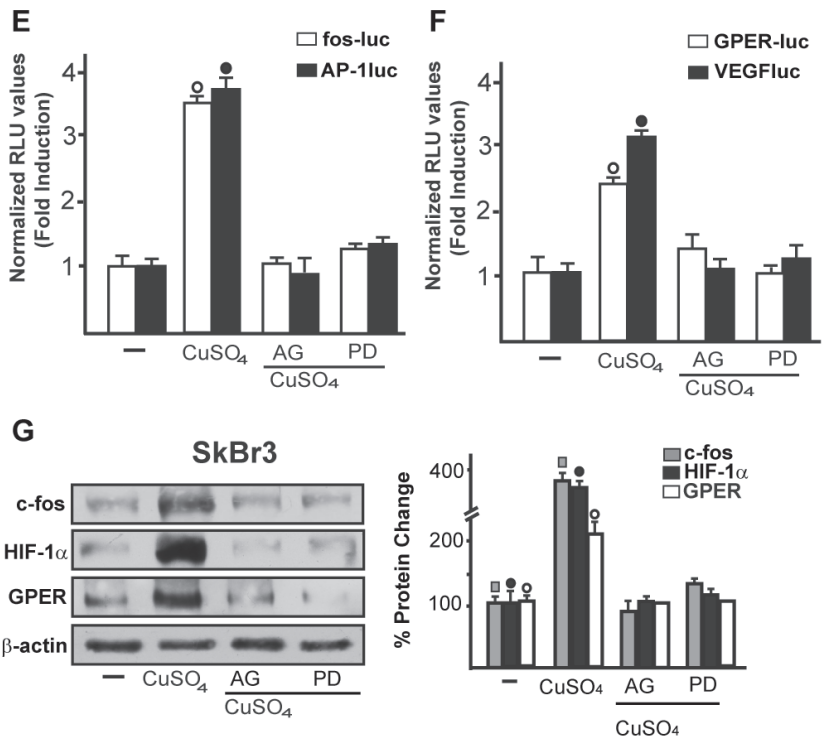

H
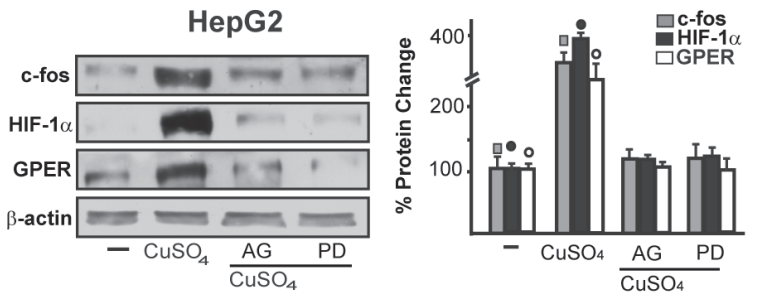

Figure 6: The EGFR/ERK transduction pathway is involved in the stimulatory responses induced by $\mathrm{CuSO}_{4}$. The mRNA increase of c-fos A., HIF-1 $\alpha$ B., GPER C. and VEGF D. observed in SkBr3 and HepG2 cells upon treatment with $200 \mu \mathrm{M} \mathrm{CuSO}_{4}$ for 8 hours is prevented by $\mathrm{AG}(10 \mu \mathrm{M})$ and PD $(10 \mu \mathrm{M})$, as evaluated by real-time PCR. Values are normalized to the $18 \mathrm{~S}$ expression and shown as fold changes of mRNA expression induced by $\mathrm{CuSO}_{4}$ compared to cells treated with vehicle (-). The transactivation of c-fos, AP-1, GPER and VEGF reporter plasmids induced in SkBr3 cells upon treatment with $200 \mu \mathrm{M} \mathrm{CuSO}_{4}$ for 12 hours is abolished using AG $(10 \mu \mathrm{M})$ and PD $(10 \mu \mathrm{M})$ E., F. The luciferase activities were normalized to the internal transfection control and values of cells receiving vehicle (-) were set as 1-fold induction upon which the activities induced by $\mathrm{CuSO}_{4}$ treatment were calculated. Each data point represents the mean $\pm \mathrm{SD}$ of three independent experiments performed in triplicate. The up-regulation of c-fos, HIF-1 $\alpha$ and GPER protein expression observed in SkBr3 G. and HepG2 H. cells treated with $200 \mu \mathrm{M} \mathrm{CuSO}_{4}$ for 8 hours is abolished in the presence of $\mathrm{AG}(10 \mu \mathrm{M})$ and PD $(10 \mu \mathrm{M})$ G., H. Results shown are representative of three independent experiments. Side panels show densitometric analysis of the blots normalized to $\beta$-actin. ( $\square),(\bullet)(0), p<0.05$ for cells receiving vehicle (-) versus $\mathrm{CuSO}_{4}$ treatment. 


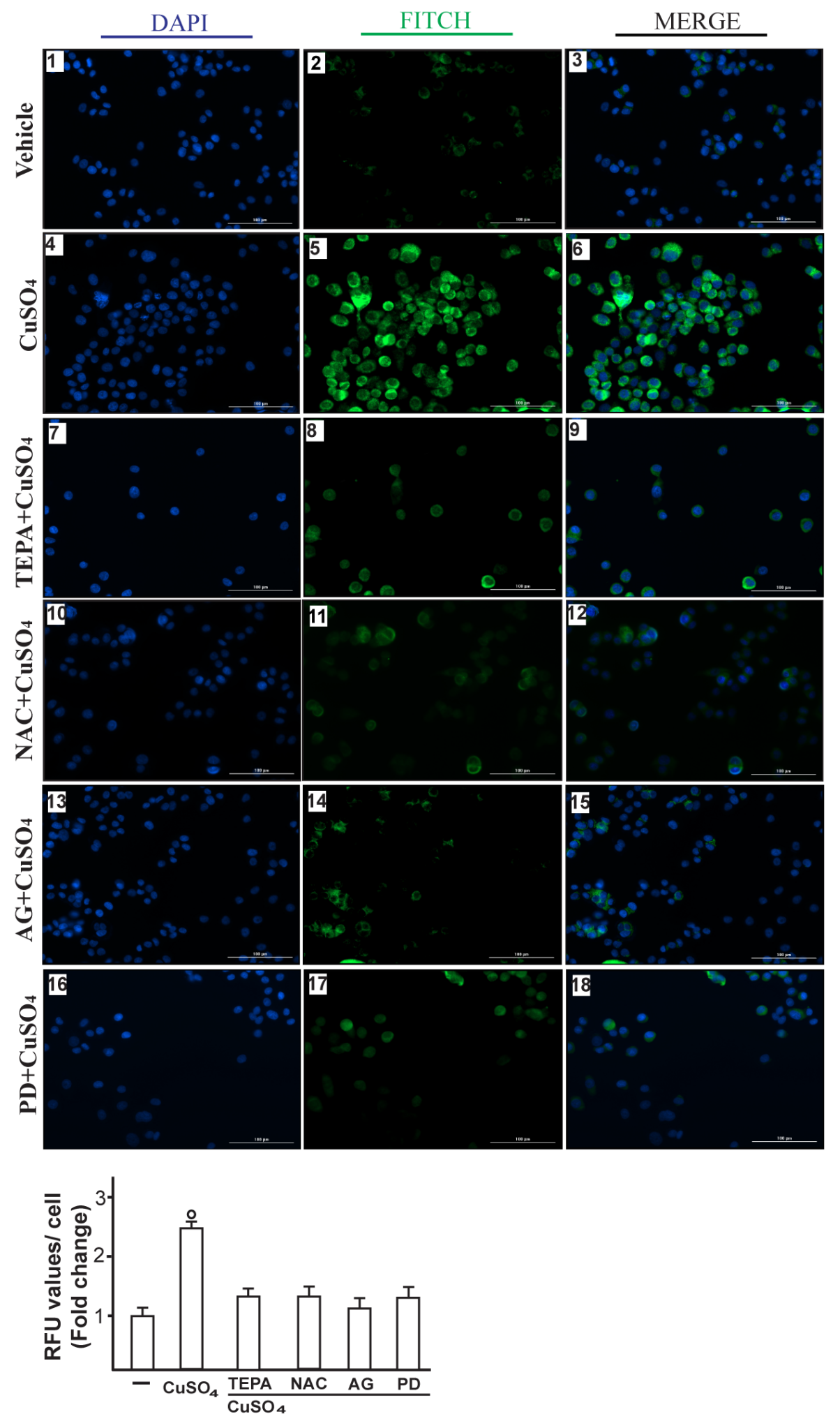

Figure 7: $\mathrm{CuSO}_{4}$ induces VEGF protein expression as evaluated by immunofluorescence assay. $\mathrm{SkBr} 3$ cells were treated for 12 hours with vehicle (panels 1-3), $200 \mu \mathrm{M} \mathrm{CuSO}_{4}$ alone (panels 4-6) or in combination with TEPA (50 $\mu \mathrm{M}$ ) (panels 7-9), NAC (300 $\mu \mathrm{M})$ (panels 10-12), AG (10 $\mu \mathrm{M})$ (panels 13-15) and PD (10 $\mu \mathrm{M})$ (panels 16-18). VEGF accumulation is shown by the green signal, nuclei were stained by DAPI (blue signal). The slides were imaged on the Cytation 3 Cell Imaging Multimode Reader (BioTek, Winooski, VT). Images shown are representative of three independent experiments. Fluorescence intensities for the green channel were quantified in 10 random fields for each condition and results are expressed as fold change of relative fluorescence units (RFU) over the vehicle-treated cells (as indicated in the lower panel). Values are mean \pm SD of three independent experiments. $(\circ) p<0.05$ for cells receiving vehicle (-) versus $\mathrm{CuSO}_{4}$ treatment. 

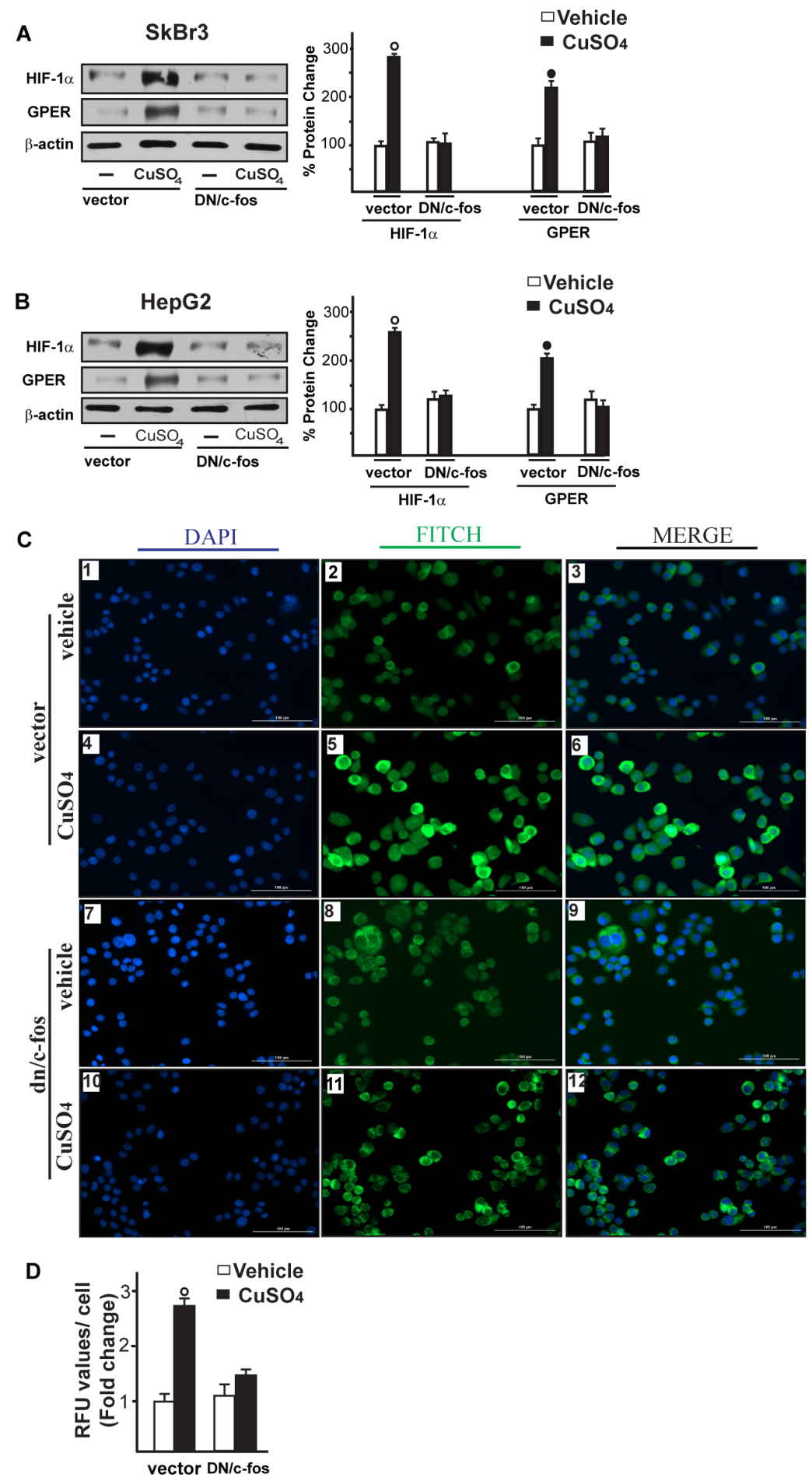

Figure 8: c-fos is involved in the up-regulation of HIF-1 $\alpha$, GPER and VEGF induced by $\mathrm{CuSO}_{4}$. Evaluation of HIF-1 $\alpha$ and GPER protein expression in SkBr3 and HepG2 cells transfected for 24 hours with a vector or a plasmid encoding for a dominant negative form of c-fos (DN/c-fos) and then treated with $200 \mu \mathrm{M} \mathrm{CuSO}_{4}$ for 8 hours (A., B.). Side panels show densitometric analysis of the blots normalized to $\beta$-actin. Each data point represents the mean $\pm \mathrm{SD}$ of three independent experiments. Evaluation of VEGF protein expression by immunofluorescence assay in $\mathrm{SkBr} 3$ cells transfected for 24 hours with a vector (panels 1-6) or a plasmid encoding for a dominant negative form of c-fos (DN/c-fos) (panels 7-12) and then treated with vehicle or $200 \mu \mathrm{M} \mathrm{CuSO}_{4}$ for 12 hours, as indicated. VEGF accumulation is shown by the green signal, nuclei were stained by DAPI (blue signal). The slides were imaged on the Cytation 3 Cell Imaging Multimode Reader (BioTek, Winooski, VT). Images shown are representative of three independent experiments C. Fluorescence intensities for the green channel were quantified in 10 random fields for each condition and results are expressed as fold change of relative fluorescence units (RFU) over the vehicle-treated cells $\mathbf{D}$. Values are mean $\pm \mathrm{SD}$ of three independent experiments. $(\circ),(\bullet) p<0.05$ for cells receiving vehicle (-) versus $\mathrm{CuSO}_{4}$ treatment. 
A

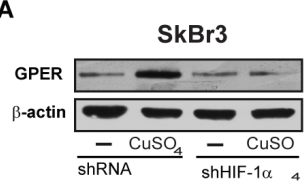
HIF-1
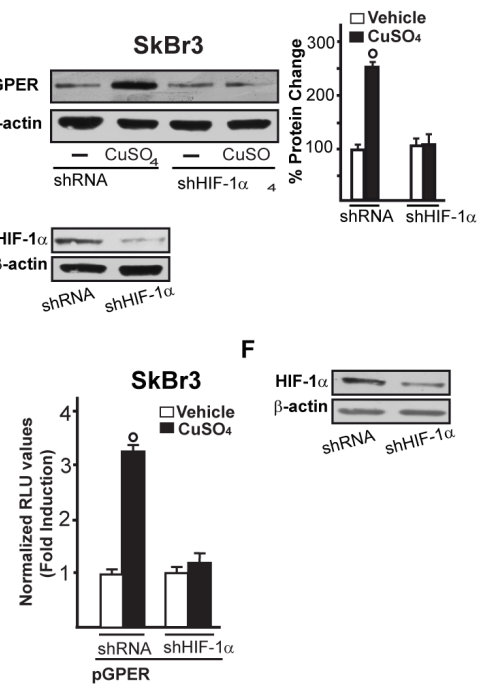

C

D HIF-1 $\alpha$

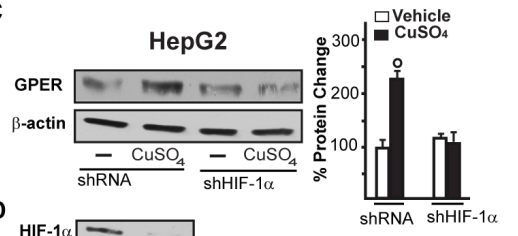

G

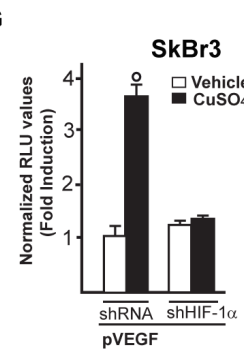

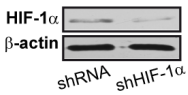
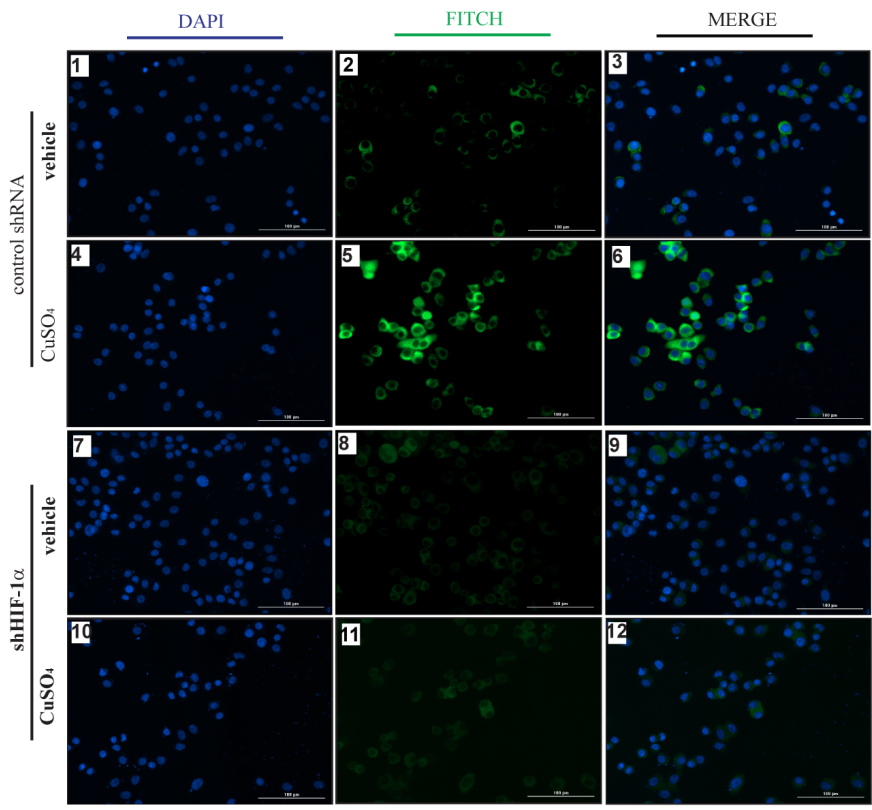

$\mathbf{J}$

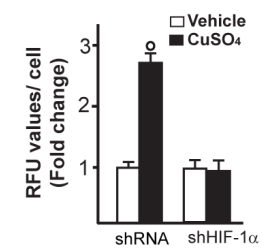

K

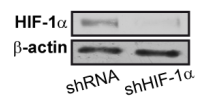

$\underset{\operatorname{shRNA} \text { shHIF-10 }}{\longrightarrow}$

RNA ShHIF-1 2 (n)

Figure 9: HIF-1 $\alpha$ is involved in the up-regulation of GPER and VEGF induced by $\mathrm{CuSO}_{4}$. Evaluation of GPER protein expression in $\mathrm{SkBr} 3$ and $\mathrm{HepG} 2$ cells transfected with shRNA or shHIF-1 $\alpha$ for 24 hours and then treated with $200 \mu \mathrm{M} \mathrm{CuSO}_{4}$ for 8 hours A., C. Side panels show densitometric analysis of the blots normalized to $\beta$-actin. Efficacy of HIF-1 $\alpha$ silencing in $\mathrm{SkBr} 3$ and HepG2. Each data point represents the mean \pm SD of three independent experiments B., D. E.-H. The transactivation of the GPER (pGPER) E. and VEGF (pVEGF) G. promoter plasmids observed in $\mathrm{SkBr} 3$ cells treated with $200 \mu \mathrm{M} \mathrm{CuSO}_{4}$ for 12 hours is abrogated silencing the expression of HIF-1 $\alpha$. (F, H) Efficacy of HIF-1 $\alpha$ silencing. The luciferase activities were normalized to the internal transfection control and values of cells receiving vehicle were set as 1-fold induction, upon which the activities induced by treatments were calculated. Each data point represents the mean \pm SD of three independent experiments performed in triplicate. I. Evaluation of VEGF protein expression by immunofluorescence assay in $\mathrm{SkBr} 3$ cells transfected for 24 hours with shRNA (panels 1-6) or shHIF-1 $\alpha$ (panels 7-12) and treated with $200 \mu \mathrm{M} \mathrm{CuSO}_{4}$ for 12 hours, as indicated. VEGF accumulation is shown by the green signal, nuclei were stained by DAPI (blue signal). The slides were imaged on the Cytation 3 Cell Imaging Multimode Reader (BioTek, Winooski, VT). Images shown are representative of three independent experiments. J. Fluorescence intensities for the green channel were quantified in 10 random fields for each condition and results are expressed as fold change of relative fluorescence units (RFU) over the vehicle-treated cells. Values are mean \pm SD of three independent experiments. K. Efficacy of HIF-1 $\alpha$ silencing. ( $(\circ) p<0.05$ for cells receiving vehicle versus $\mathrm{CuSO}_{4}$ treatment. 
we demonstrated that a functional cooperation between HIF- $1 \alpha$ and GPER contributes to VEGF regulation in cancer cells exposed to copper. Recalling previous studies on the capability of copper chelating agents to elicit anti- tumor effects [5, 32], we have also evidenced that these chemicals exert an inhibitory action on HIF-1 $\alpha /$ GPER/ VEGF transduction pathway. Next, we have found that HIF- $1 \alpha$ and GPER are required for endothelial tube
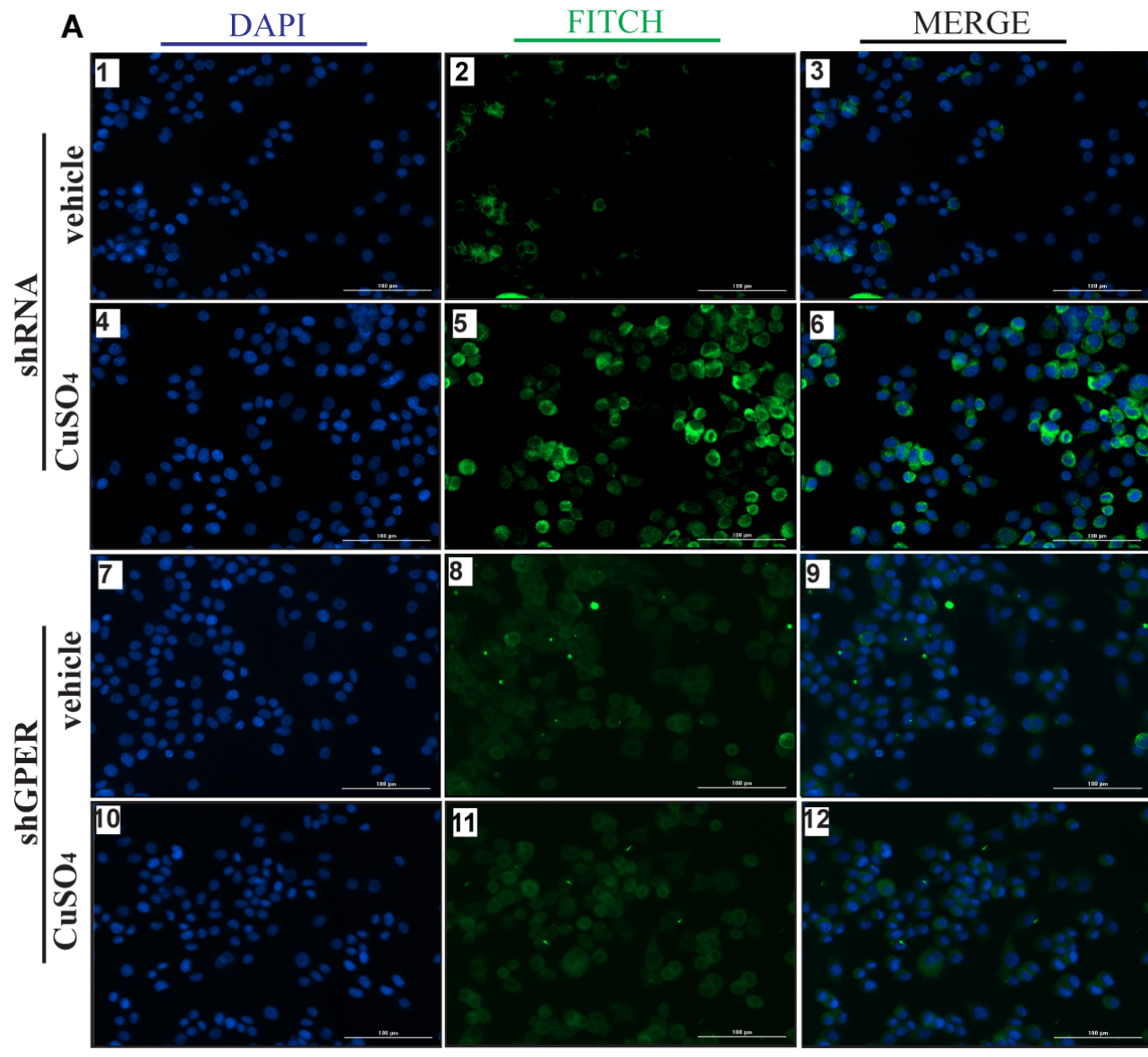

B

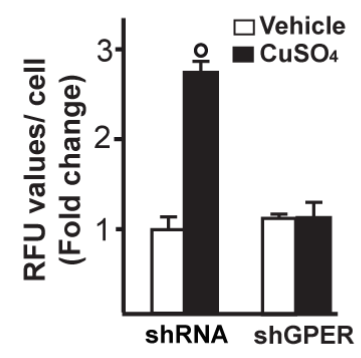

C

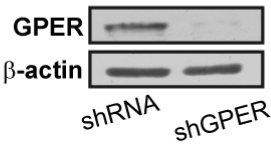

D

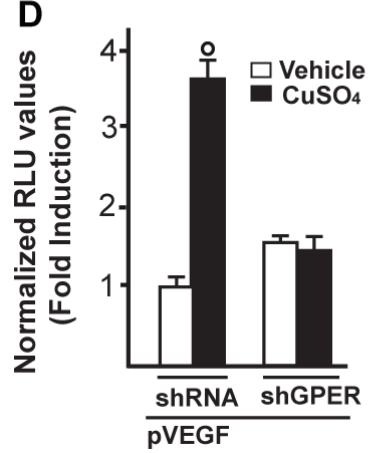

E

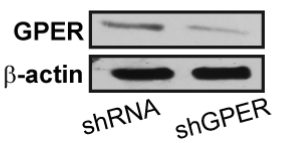

Figure 10: GPER is involved in VEGF protein increase induced by $\mathrm{CuSO}_{4}$. Evaluation of VEGF protein expression by immunofluorescence assay in SkBr3 cells transfected for 24 hours with shRNA (panels 1-6) or shGPER (panels 7-12) and treated with 200 $\mu \mathrm{M} \mathrm{CuSO}_{4}$ for 12 hours, as indicated. VEGF accumulation is evidenced by the green signal, nuclei were stained by DAPI (blue signal). The slides were imaged on the Cytation 3 Cell Imaging Multimode Reader (BioTek, Winooski, VT). Images shown are representative of three independent experiments A. Fluorescence intensities for the green channel were quantified in 10 random fields for each condition and results are expressed as fold change of relative fluorescence units (RFU) over the vehicle-treated cells $\mathbf{B}$. Values are mean \pm SD of three independent experiments. Efficacy of GPER silencing $\mathbf{C}$. The transactivation of the VEGF (pVEGF) promoter plasmid observed in SkBr3 cells treated with $200 \mu \mathrm{M} \mathrm{CuSO}_{4}$ for 12 hours is abrogated silencing the expression of GPER D. The luciferase activities were normalized to the internal transfection control and values of cells receiving vehicle were set as 1-fold induction, upon which the activities induced by treatments were calculated. Efficacy of GPER silencing E. Each data point represents the mean \pm SD of three independent experiments performed in triplicate. ( $\left(\right.$ ) $p<0.05$ for cells receiving vehicle (-) versus $\mathrm{CuSO}_{4}$ treatment. 
formation and cell migration stimulated by VEGF as well as for copper-induced proliferation of breast cancer cells.

The role of copper in tumor initiation and progression has been extensively investigated both in vitro and in vivo $[8,33]$. In this context, high copper levels ranging from 50 to $200 \mu \mathrm{M}$ have been correlated with incidence and recurrence in cancer patients $[8,9]$. In accordance with these findings, we have ascertained

\section{HUVECs}

A

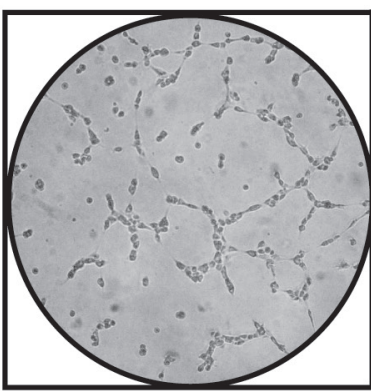

medium from $\mathrm{SkBr} 3$ cells treated with vehicle

shRNA

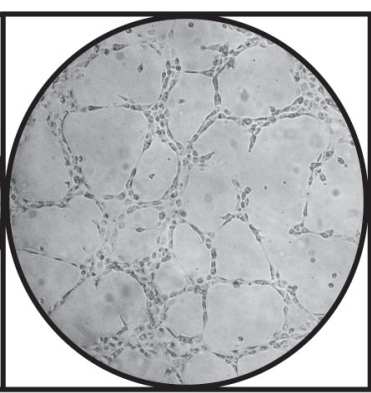

medium from $\mathrm{SkBr} 3$ cells treated with $\mathrm{CuSO}_{4}$

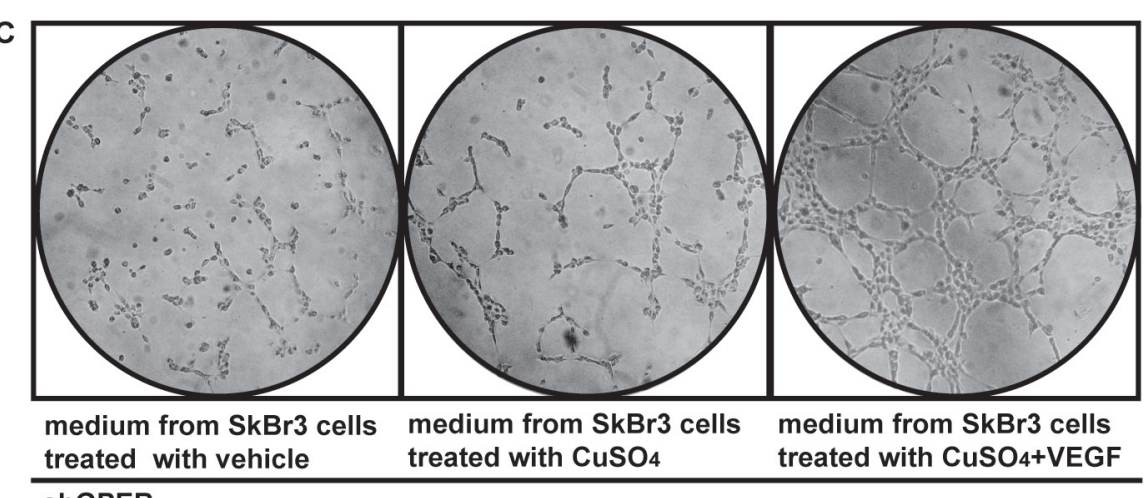

shGPER

D

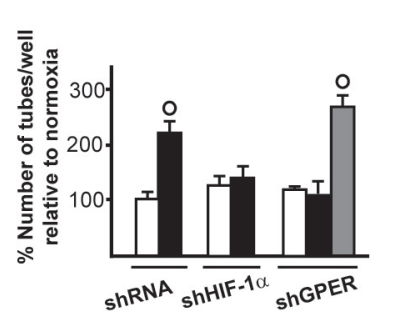

E

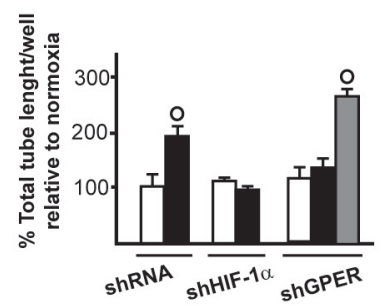

F

$\square$ medium from SkBr3 cells treated with vehicle

medium from $\mathrm{SkBr} 3$ cells treated with $\mathrm{CuSO}_{4}$

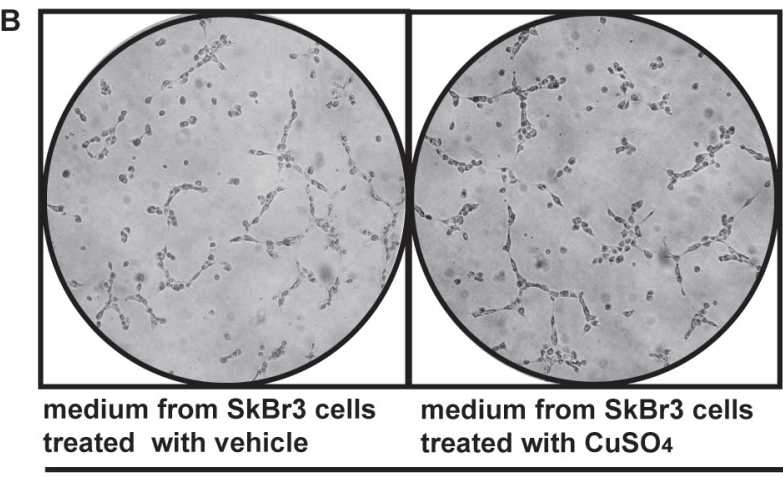

shHIF-1 $\alpha$ medium from $\mathrm{SkBr} 3$ cells treated with $\mathrm{CuSO}_{4}$

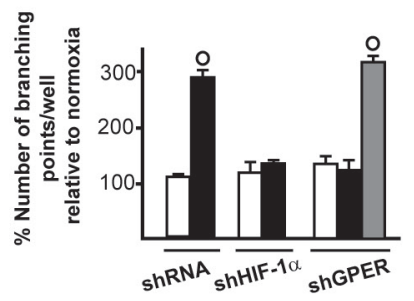

$\square$ medium from SkBr3 cells treated with $\mathrm{CuSO}_{4}+$ VEGF
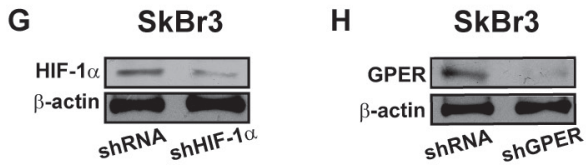

Figure 11: HIF-1 $\alpha$ and GPER contribute to the endothelial tube formation triggered by $\mathrm{CuSO}_{4}$. Tube formation in HUVECs cultured for 2 hours in medium collected from SkBr3 cells which were transfected for 24 hours with shRNA A., shHIF-1 $\alpha$ B. or shGPER C. and then treated for 18 hours with vehicle or $200 \mu \mathrm{M} \mathrm{CuSO}_{4}$, as indicated. C. In HUVECs cultured in conditioned medium from $\mathrm{SkBr} 3$ cells that were transfected with shGPER and treated with $200 \mu \mathrm{M} \mathrm{CuSO}_{4}$ tube formation is rescued adding $10 \mathrm{ng} / \mathrm{mL}$ VEGF for 2 hours. Data are representative of three independent experiments performed in triplicate. Quantification of the number of tubes D., total tube length E. and number of branching points F. observed in HUVECs, as indicated. Data are representative of three independent experiments performed in triplicate. ( ( ) $p<0.05$ for cells receiving medium from $\mathrm{SkBr} 3$ cells treated with vehicle versus cells receiving medium from $\mathrm{SkBr} 3$ cells treated with $\mathrm{CuSO}_{4}$. Efficacy of HIF-1 $\alpha$ G. and GPER H. silencing in $\mathrm{SkBr} 3$ cells. 
that copper exerts stimulatory effects on gene expression starting from a concentration of $25 \mu \mathrm{M}$, even though the maximal responses were observed using a concentration of $200 \mu \mathrm{M}$. Hence, the last amount was used in all assays to better evaluate the potential of copper to activate the aforementioned biological activity. Previous studies have disclosed that certain effects elicited by copper in cancer cells rely on the generation of reactive oxygen species (ROS), which act as second messenger in triggering stimulatory signals [8]. In this regard, it has been shown the transduction mechanisms involved, that include the activation of the EGFR/ERK pathway and the expression of genes mediating growth responses like c-fos [reviewed in 5]. On the basis of these observations, it could be argued that copper may mimic some biological features which characterize the hypoxic tumor environment.

HIF-1 acts as a survival factor upon low oxygen conditions regulating the expression of genes involved in cell metabolism, migration, invasion and angiogenesis [34-35]. In this vein, it is worth mentioning that copper was shown to increase HIF-1 $\alpha$ stabilization and accumulation [19]. Further extending these findings, our current results indicate that copper is also able to induce HIF-1 $\alpha$ expression, thus providing a new mechanism through which this chemical may be involved in cancer progression. Previous studies have determined that GPER contributes together with HIF-1 $\alpha$ to the adaptive responses to hypoxic tumor microenvironment $[17,24]$. Nicely fitting with these observations, the present data reveal that copper induces the expression of GPER through HIF-1 $\alpha$, leading to the regulation of VEGF in breast cancer cells and cancer associated fibroblasts (CAFs) [17]. The stimulatory role of copper in cancer development has been also proved by copper chelating agents as a reduction in tumor volume, vascular permeability, tumor's microvascular supply and micrometastasis generation has been reported

\section{HUVECs}

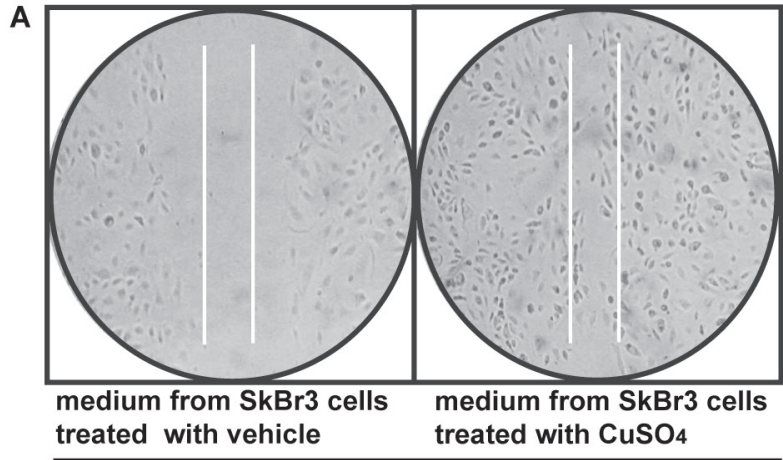

ShRNA

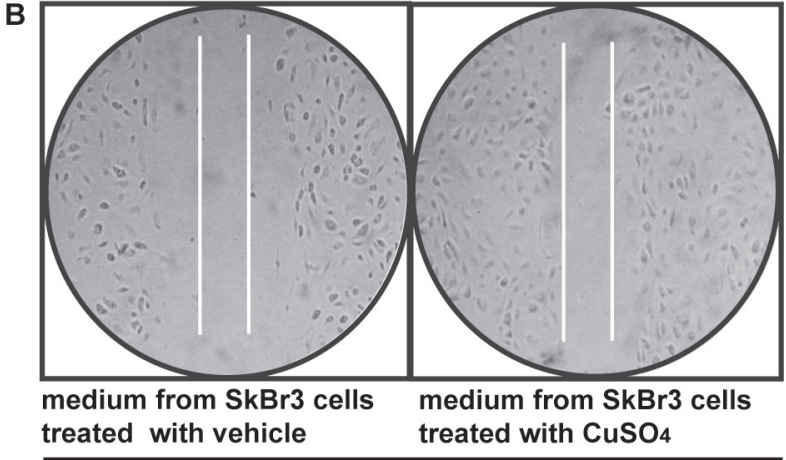

shHIF-1 $\alpha$

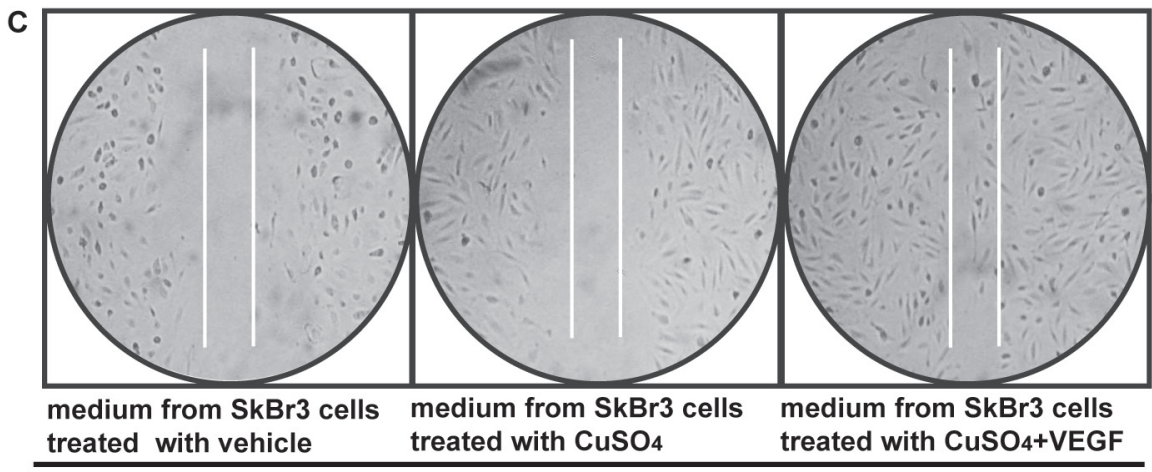

shGPER
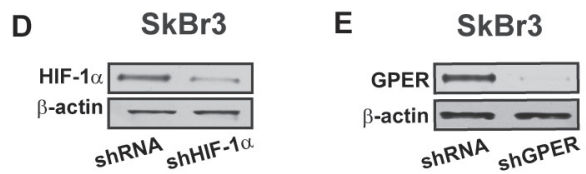

Figure 12: HIF-1 $\alpha$ and GPER contribute to the endothelial cell migration induced by $\mathrm{CuSO}_{4}$. Cell migration in $\mathrm{HUVECs}$ cultured for 24 hours in medium collected from SkBr3 cells which were transfected for 24 hours with control shRNA A., shHIF-1 $\alpha$ B. or shGPER C. and then treated for 18 hours with vehicle or $200 \mu \mathrm{M} \mathrm{CuSO}_{4}$, as indicated. C. In HUVECs cultured in medium from SkBr3 cells which were transfected with shGPER and treated with $200 \mu \mathrm{M} \mathrm{CuSO}_{4}$ cell migration is rescued adding $10 \mathrm{ng} / \mathrm{mL}$ VEGF for 36 hours. Data are representative of three independent experiments performed in triplicate. Efficacy of HIF-1 $\alpha$ D. and GPER E. silencing in $\mathrm{SkBr} 3$ cells. 
lowering copper levels in diverse experimental models [5]. Extending the current knowledge on the action of anti-copper drugs like TEPA, our data indicate that these chemicals may also target HIF-1 $\alpha /$ GPER signalling among the multifaceted responses triggered in cancer cells.

To date, the expression of GPER has been associated with negative clinical features and poor survival rates in a variety of tumors [36-38]. Consequently, huge efforts are currently underway to better understand the mechanisms involved in the regulation of GPER $[28,39$ 58] which belongs to the GPCRs family widely involved in cancer progression $[59,60]$. Of note, several studies have demonstrated that estrogenic GPER signalling mediates relevant biological effects like proliferation and migration in cancer cells and CAFs [61-63] that are largely acknowledged to contribute to tumor cell metabolism and disease progression [64-66]. In this regard, additional investigations are needed to determine whether copper could be also able to activate GPER signalling in a direct manner, as previously demonstrated using other metals [67].

Here, we have provided novel evidence regarding the action elicited by copper toward tumor angiogenesis and progression. On the basis of the present findings GPER may be included together with HIF-1 $\alpha$ and VEGF among the molecular targets of copper chelating agents in combination therapies. Nevertheless, further studies are needed to better define the role of copper on the functional interaction between GPER, HIF-1 $\alpha$ and VEGF in malignant cells and tumor microenvironment.

\section{MATERIALS AND METHODS}

\section{Materials}

Copper sulfate $\left(\mathrm{CuSO}_{4}\right)$, cobalt chloride $\left(\mathrm{CoCl}_{2}\right)$, tetraethylenepentamine (TEPA) and ROS scavenger N-acetyl-L-cysteine (NAC) were purchased from SigmaAldrich Srl (Milan, Italy). Tyrphostin AG1478 (AG) was purchased from Biomol Research Laboratories, Inc (Milan, Italy). PD98059 (PD) was obtained from Calbiochem (Milan, Italy). Human VEGF was purchased from Peprotech (Rocky Hill, New Jersey, USA). All compounds were dissolved in DMSO, except VEGF, $\mathrm{CuSO}_{4}$ and NAC which were solubilized in water.

\section{Cell cultures}

We used SkBr3 breast cancer cells and HepG2 hepatocarcinoma cells that represent a valuable tool for the evaluation of the transduction pathways activated by copper in cancer cells. As both cell lines express GPER, which has been involved with the angiogenic process within the tumor microenvironment [17-18], this model system is suitable to ascertain the contribution of GPER to copper action toward tumor angiogenesis.

The SkBr3 breast cancer cells were maintained in RPMI-1640 (Life Technologies, Milan, Italy) without phenol red, supplemented with $10 \%$ fetal bovine serum (FBS) and $100 \mu \mathrm{g} / \mathrm{ml}$ penicillin/streptomycin. The hepatocarcinoma cells HepG2 were cultured in DMEM (Dulbecco's modified Eagle's medium) (Life Technologies, Milan, Italy) with phenol red, supplemented with $10 \% \mathrm{FBS}$ and $100 \mu \mathrm{g} / \mathrm{ml}$ penicillin/streptomycin. Human umbilical vein endothelial cells (HUVECs) were seeded on collagen-coated flasks (Sigma-Aldrich Srl, Milan, Italy) and cultured in Endothelial Growth Medium (EGM) (Lonza, Milan, Italy), supplemented with 5\% FBS (Lonza, Milan, Italy). All cell lines were grown in a $37^{\circ}$ C HeraCell incubator (ThermoScientific-Heraeus, Milan, Italy) with $5 \% \mathrm{CO}_{2}$. For hypoxic stimulation, cells were treated with $\mathrm{CoCl}_{2}(100 \mu \mathrm{M})$ or cultured in the presence of a low oxygen tension $\left(2 \% \mathrm{O}_{2}\right)$ in a multi-gas HeraCell incubator (ThermoScientific-Heraeus, Milan, Italy). Cells were switched to medium without serum the day before experiments.

\section{Gene reporter assays}

The $2.6 \mathrm{~kb}$ VEGF promoter-luciferase construct containing full-length VEGF promoter sequence $(22,361$ to +298 bp relative to the transcription start site) used in luciferase assays was a kind gift from dr. P. Soumitro (Harvard Medical School, Boston, Massachusetts). The GPER promoter-luciferase construct (pGPER 2.9 kb) was obtained as previously described [24].

The luciferase reporter plasmid for AP-1 responsive collagen promoter was a kind gift from H. Van Dam (Department of Molecular Cell Biology, Leiden University, Leiden, Netherlands). The luciferase reporter plasmid for c-fos, encoding a $-2.2 \mathrm{~kb} 5$ ' upstream fragment of human c-fos, kindly provided by K. Nose (Department of Microbiology, Showa University School of Pharmaceutical Sciences, Hatanodai, Shinagawa-ku, Tokyo, Japan). SkBr3 and HepG2 cells (1 x 10 $0^{5}$ were plated into 24 -well dishes with $500 \mu \mathrm{L} /$ well culture medium containing 10\% FBS. Transfections were performed using X-treme GENE 9 DNA transfection reagent as recommended by the manufacturer (Roche Diagnostics, Milan, Italy), with a mixture containing $0.5 \mu \mathrm{g}$ of reporter plasmid and $10 \mathrm{ng}$ of pRL-TK. After 24 h, cells were treated with $\mathrm{CuSO}_{4}$, alone and in combination with TEPA, NAC, AG1478 and PD98059, as indicated. For co-transfection experiments, cells were previously transfected with control shRNA, shHIF-1 $\alpha$ or shGPER using X-treme GENE 9 DNA transfection reagent (Roche Diagnostics, Milan, Italy). A mixture containing 0.5 $\mu \mathrm{g}$ of reporter plasmid and $10 \mathrm{ng}$ of $\mathrm{pRL}-\mathrm{TK}$ was then transfected by using X-treme GENE 9 DNA Transfection. After 8 hours, cells were treated for 18 hours with $\mathrm{CuSO}_{4}$ 
in serum free medium. Luciferase activity was measured with the Dual Luciferase Kit (Promega, Milan, Italy) normalized to the internal transfection control provided by Renilla luciferase activity. The normalized relative light unit values obtained from cells treated with vehicle were set as 1 -fold induction, upon which the activity induced by treatments was calculated.

\section{Gene expression studies}

Total RNA was extracted from cell cultures using the TRIzol commercial kit (Life Technologies, Milan, Italy) according to the manufacturer's protocol. RNA was quantified spectrophotometrically and quality was checked by electrophoresis through agarose gels stained with ethidium bromide. Only samples that were not degraded and showed clear 18 and $28 \mathrm{~S}$ bands under UV light were used for RT-PCR. Total cDNA was synthesized from the RNA by reverse transcription as previously described [17]. The expression of selected genes was quantified by real-time PCR using Step One (TM) sequence detection system (Applied Biosystems Inc, Milan, Italy), following the manufacturer's instructions. Gene-specific primers were designed using Primer Express version 2.0 software (Applied Biosystems. Inc., Milan, Italy) and are as follows: : HIF-1 $\alpha$ Fwd: 5'-TGCATCTCCATCTTCTACCCAAGT-3' and Rev: 5'-CCGACTGTGAGTGCCACTGT-3'; VEGF Fwd: 5'- TGCAGATTATGCGGATCAAACC-3' and Rev: 5'- TGCATTCACATTTGTTGTGCTGTAG-3'; GPER Fwd: 5'-CCTGGACGAGCAGTATTACGATATC-3' and Rev 5'-TGCTGTACATGTTGATCTG-3'; c-FOS Fwd: 5'-GAGCCCTTTGATGACTTCCT-3' and Rev: 5'-GAGCGGGCTGTCTCAGA-3'; 18S Fwd: 5'- GGCGTCCCCCAACTTCTTA -3' and Rev: 5'GGGCATCACAGACCTGTTATT -3'. Assays were performed in triplicate and the results were normalized for $18 \mathrm{~S}$ expression and then calculated as fold induction of RNA expression.

\section{Western blot analysis}

SkBr3 and HepG2 cells were processed according to the previously described protocol [17] to obtain protein lysate that was electrophoresed through a reducing SDS $/ 10 \%(w / v)$ polyacrylamide gel, electroblotted onto a nitrocellulose membrane and probed with primary antibodies against HIF-1 $\alpha$ (R\&D Systems, Inc. Celbio, Milan, Italy), GPER (N-15), c-fos (H-125), phosphorylated ERK 1/2 (E-4), ERK2 (C-14), EGFR (1005), pEGFR Tyr 1173 (sc-12351-R) and $\beta$-actin (C2), all purchased from Santa Cruz Biotechnology, (DBA, Milan, Italy). Proteins were detected by horseradish peroxidase-linked secondary antibodies (Santa Cruz Biotecnology, DBA) and revealed using the ECL System (GE Healthcare).

\section{Gene silencing experiments}

Cells were plated onto $10-\mathrm{cm}$ dishes and prior to treatments cells were transfected for 24 hours using X-treme GENE 9 DNA Transfection Reagent (Roche Diagnostics, Milan, Italy) with a control shRNA, shHIF$1 \alpha$, shGPER, a control vector and the plasmid DN/c-fos, encoding a c-fos mutant that heterodimerizes with c-fos dimerization partners but not allowing DNA binding (kindly obtained from Dr. C. Vinson, NIH, Bethesda, MD, USA). The HIF- $1 \alpha$ shRNA and the respective control plasmid were purchased from SABioscience Corporation (Frederick, MD, USA). The silencing of GPER expression was obtained by the construct which we have previously described and used [68].

\section{Immunofluorescence assay}

Fifty percent confluent cultured SkBr3 cells grown on coverslips were serum deprived and then treated for 12 hours with $\mathrm{CuSO}_{4}$ alone and in combination with TEPA, NAC, AG1478 and PD98059, as indicated. Where required, cells previously transfected for $24 \mathrm{~h}$ with shHIF$1 \alpha$ or shGPER and respective negative control plasmids (as described above) and then treated for 18 hours with $\mathrm{CuSO}_{4}$, Then cells were fixed in $4 \%$ paraformaldehyde, permeabilized with $0.2 \%$ Triton $\mathrm{X}-100$, washed three times with PBS and incubated overnight with a mouse primary antibody against VEGF (C-1) (Santa Cruz Biotechnology, DBA, Milan, Italy). After incubation, the slides were extensively washed with PBS and incubated with 4',6-diamidino-2-phenylindole dihydrochloride (DAPI), (1:1000), (Sigma-Aldrich, Milan, Italy) and donkey anti-mouse IgG-FITC (1:300; purchased from Alexa Fluor, Life Technologies, Milan, Italy). The slides were imaged on the Cytation 3 Cell Imaging Multimode reader (BioTek, Winooski, VT) and analysed using the software Gen5 (BioTek, Winooski, VT).

\section{Conditioned medium}

$\mathrm{SkBr} 3$ cells were cultured in regular growth medium, then cells were washed twice with PBS and transfected for 24 hours in serum-free RPMI-1640 with shHIF-1 $\alpha$, shGPER or control shRNA using X-treme GENE 9 DNA Transfection Reagent (Roche Diagnostics, Milan, Italy). Cells were treated for 18 hours with $\mathrm{CuSO}_{4}$, culture medium was then replaced for additional 18 hours with medium without serum. Thereafter, the supernatants were collected, centrifuged at 3,500 rpm for 5 minutes to remove cell debris and used as conditioned medium in HUVECs. 


\section{Tube formation assay}

The day before the experiment, confluent HUVECs were starved overnight at $37{ }^{\circ} \mathrm{C}$ in serum free medium (EBM, Lonza, Milan, Italy). Growth factor-reduced Matrigel ${ }^{\circledR}$ (Cultrex, Trevigen Inc, USA) was thawed overnight at $4{ }^{\circ} \mathrm{C}$ on ice, plated on the bottom of prechilled 96well-plates and left at $37^{\circ} \mathrm{C}$ for $1 \mathrm{~h}$ for gelification. Starved HUVECs were collected by enzymatic detachment ( $0.25 \%$ trypsin-EDTA solution, Life Technologies, Milan, Italy), counted and resuspended in conditioned medium from CAFs. Then, 10,000 cells/well were seeded on Matrigel and incubated at $37^{\circ} \mathrm{C}$. Tube formation was observed starting from $2 \mathrm{~h}$ after cell seeding and quantified by using the software NIH ImageJ (National Institutes of Health (NIH), Rockville Pike, Bethesda, Maryland, USA)

\section{Migration assay}

Twelve-well plates were coated with $500 \mu \mathrm{L}$ fibronectin for 2 hours at $37^{\circ} \mathrm{C}$ (Sigma Aldrich, Milan, Italy). HUVECs were allowed to grow in regular growth medium until they reached a $70 \%$ to $80 \%$ confluence. Next, to create a scratch of the cell monolayer, a p200 pipette tip was used. Cells were washed twice with PBS and then incubated in medium collected from $\mathrm{SkBr} 3$ cells as previously described. The migration assay was evaluated after 24 hours of treatment.

\section{MTT growth assay}

For quantitative proliferation assay, cells (1 x $10^{5}$ ) were seeded in 24-well plates in regular growth medium. Cells were washed once they had attached and then incubated in medium containing $2.5 \%$ charcoalstripped FBS with the indicated treatments; medium was renewed every day (with treatments) before dimethylthiazoldiphenyltetrazoliumbromide (MTT, Sigma-Aldrich, Milan, Italy) assay which was performed according to the manufacturer's protocol. A concentration of $250 \mathrm{ng} / \mathrm{L}$ of the control shRNA, shHIF-1 $\alpha$ or shGPER plasmids was transfected using X-treme GENE 9 DNA Transfection Reagent the day before treatments. The absorbance was measured using a FLX-800 microplate fluorimeter (Bio-Tek Instruments, Inc., Winooski, VT, USA) at a test wavelength of $570 \mathrm{~nm}$. Each experiment was performed at in triplicate.

\section{Statistical analysis}

Statistical analysis was performed using ANOVA followed by Newman-Keuls' testing to determine differences in means. $p<0.05$ was considered statistically significant.

\section{ACKNOWLEDGMENTS AND FUNDING}

This work was supported by Associazione Italiana per la Ricerca sul Cancro (AIRC), PROGRAMMA OPERATIVO NAZIONALE "RICERCA E COMPETITIVITA' 2007-2013" (PON01_01078) and Ministero della Salute (grant n. 67/GR-2010-2319511).

\section{CONFLICTS OF INTERESTS}

The authors declare no conflict of interest.

\section{REFERENCES}

1. Kim BE, Nevitt T, Thiele DJ. Mechanisms for copper acquisition, distribution and regulation. Nat Chem Biol. 2008; 3: 176-185.

2. Georgopoulos PG, Roy A, Yonone-Lioy MJ, Opiekun RE, Lioy PJ. Environmental copper: its dynamics and human exposure issues. J Toxicol Environ Health B Crit Rev. 2001; 4: 341-394.

3. Agency for Toxic Substances and Disease Registry. Toxicological Profile for Copper. Atlanta, GA: US Public Health Service, 1990, p. 43.

4. Rocha GH, Lini RS, Barbosa F Jr, Batista BL, de Oliveira Souza VC, Nerilo SB, Bando E, Mossini SA, Nishiyama P. Exposure to heavy metals due to pesticide use by vineyard farmers. Int Arch Occup Environ Health. 2015; 88:875-80.

5. Antoniades V, Sioga A, Dietrich EM, Meditskou S, Ekonomou L, Antoniades K. Is copper chelation an effective anti-angiogenic strategy for cancer treatment? Med Hypotheses. 2013; 6: 1159-1163.

6. Sabharwal SS, Schumacker PT. Mitochondrial ROS in cancer: initiators, amplifiers or an Achilles' heel? Nat Rev Cancer. 2014; 11: 709-721.

7. Olusi S, Al-Awadhi A, Abiaka C, Abraham M, George S. Serum copper levels and not zinc are positively associated with serum leptin concentrations in the healthy adult population. Biol Trace Elem Res. 2003; 91: 137-144.

8. Gupte A, Mumper RJ. Elevated copper and oxidative stress in cancer cells as a target for cancer treatment. Cancer Treat Rev. 2009; 1: 32-46.

9. Lewis RA, Hultquist DE, Baker BL, Falls HF, Gershowitz H, Penner JA. Hypercupremia associated with a monoclonal immunoglobulin. J Lab Clin Med. 1976; 88: 375-388.

10. Baharvand M, Manifar S, Akkafan R, Mortazavi H, Sabour S. Serum levels of ferritin, copper, and zinc in patients with oral cancer. Biomed J. 2014; 37(5):331-6.

11. Lowndes SA, Harris AL. The role of copper in tumour angiogenesis. J Mammary Gland Biol Neoplasia. 2005; 10: 299-310.

12. Finney L, Vogt S, Fukai T, Glesne D. Copper and 
angiogenesis: unravelling a relationship key to cancer progression. Clin Exp Pharmacol Physiol. 2009; 36: 88-94.

13. Sen CK, Khanna S, Venojarvi M, Trikha P, Ellison EC, Hunt TK, Roy S. Copper-induced vascular endothelial growth factor expression and wound healing. Am J Physiol Heart Circ Physiol. 2002; 282: H1821-1827.

14. Feng W, Ye F, Xue W, Zhou Z, Kang YJ. Copper regulation of hypoxia-inducible factor-1 activity. Mol Pharmacol. 2009; 1: 174-182.

15. Qiu L, Ding X, Zhang Z, Kang YJ. Copper is required for cobalt-induced transcriptional activity of hypoxia-inducible factor-1. J Pharmacol Exp Ther. 2012; 342: 561-567.

16. Richard DE, Vouret-Craviari V, Pouysségur J. Angiogenesis and G-protein-coupled receptors: signals that bridge the gap. Oncogene. 2001; 20: 1556-1562.

17. De Francesco EM, Lappano R, Santolla MF, Marsico S, Caruso A, Maggiolini M. HIF-1 $\alpha /$ GPER signalling mediates the expression of VEGF induced by hypoxia in breast cancer associated fibroblasts (CAFs). Breast Cancer Res. 2013; 15: R64.

18. De Francesco EM, Pellegrino M, Santolla MF, Lappano R, Ricchio E, Abonante S, Maggiolini M. GPER mediates activation of HIF $1 \alpha /$ VEGF signalling by estrogens. Cancer Res. 2014; 74: 4053-4064.

19. Martin F, Linden T, Katschinski DM, Oehme F, Flamme I, Mukhopadhyay CK, Eckhardt K, Tröger J, Barth S, Camenisch G, Wenger RH. Copper-dependent activation of hypoxia-inducible factor (HIF)-1: implications for ceruloplasmin regulation. Blood. 2005; 105: 4613-4619.

20. $\mathrm{Hu}$ GF. Copper stimulates proliferation of human endothelial cells under culture. J Cell Biochem. 1998; 69: 326-335.

21. Song MO, Li J, Freedman JH. Physiological and toxicological transcriptome changes in HepG2 cells exposed to copper. Physiol Genomics. 2009; 38: 386-401.

22. Dong D, Xu X, Wen Y and Kang YJ. Changes in copper concentrations affect the protein levels but not the mRNA levels of copper chaperones in human umbilical vein endothelial cells. Metallomics. 2014; 6: 554-559.

23. Sun, SY. N-acetylcysteine, reactive oxygen species and beyond. Cancer Biol. Ther. 2010; 9: 109-110.

24. Recchia AG, De Francesco EM, Vivacqua A, Sisci $\mathrm{D}$, Panno ML, Andò S, Maggiolini M. The G proteincoupled receptor 30 is up-regulated by hypoxia-inducible factor-1alpha (HIF-1alpha) in breast cancer cells and cardiomyocytes. J Biol Chem. 2011; 286: 10773-10782.

25. Maggiolini M, Vivacqua A, Fasanella G, Recchia AG, Sisci D, Pezzi V, Montanaro D, Musti AM, Picard D, Andò S. The G Protein-coupled Receptor GPR30 Mediates c-fos upregulation by $17 \mathrm{~b}$-Estradiol and Phytoestrogens in Breast Cancer Cells. J Biol Chem. 2004; 279: 27008-27016.

26. Maggiolini M, Picard D. The unfolding stories of GPR30, a new membrane-bound estrogen receptor. J Endocrinol. 2010; 204: 105-114.
27. Pandey DP, Lappano R, Albanito L, Madeo A, Maggiolini M, Picard D. Estrogenic GPR30 signalling induces proliferation and migration of breast cancer cells through CTGF. EMBO J. 2009; 28: 523-532.

28. Lappano R, De Marco P, De Francesco EM, Chimento A, Pezzi V, Maggiolini M. Cross-talk between GPER and growth factor signalling. J Steroid Biochem Mol Biol. 2013; 137: 50-56.

29. Staton CA, Reed MW, Brown NJ. A critical analysis of current in vitro and in vivo angiogenesis assays. Int J Exp Pathol. 2009; 90: 195-221.

30. Byzova TV, Goldman CK, Pampori N, Thomas KA, Bett A, Shattil SJ, Plow EF. A mechanism for modulation of cellular responses to VEGF: activation of the integrins. Mol Cell. 2000; 6: 851-860.

31. Morales-Ruiz M, Fulton D, Sowa G, Languino LR, Fujio Y, Walsh K, Sessa WC. Vascular endothelial growth factorstimulated actin reorganization and migration of endothelial cells is regulated via the serine/threonine kinase Akt. Circ Res. 2000; 86: 892-896.

32. Brewer GJ. Anticopper therapy against cancer and diseases of inflammation and fibrosis. Drug Discov Today. 2005; 10: 1103-1119.

33. Ishida S, Andreux P, Poitry-Yamate C, Auwerx J, Hanahan D. Bioavailable copper modulates oxidative phosphorylation and growth of tumors. Proc Natl Acad Sci U S A. 2013; 110: 19507-19512.

34. Wang GL, Semenza GL. General involvement of hypoxiainducible factor 1 in transcriptional response to hypoxia. Proc Natl Acad Sci USA. 1993; 90: 4304-4308.

35. Semenza GL. Hypoxia-inducible factors: mediators of cancer progression and targets for cancer therapy. Trends Pharmacol Sci. 2012; 33: 207-214.

36. Filardo EJ, Graeber CT, Quinn JA, Resnick MB, Giri D, DeLellis RA, Steinhoff MM, Sabo E. Distribution of GPR30, a seven membrane spanning estrogen receptor, in primary breast cancer and its association with clinicopathologic determinants of tumor progression. Clin Cancer Res. 2006; 12: 6359-6366.

37. Smith HO, Leslie KK, Singh M, Qualls CR, Revankar CM, Joste NE, Prossnitz ER. GPR30: a novel indicator of poor survival for endometrial carcinoma. Am J Obstet Gynecol. 2007; 196: 386.e1-9; discussion 386.e9-11.

38. Smith HO, Arias-Pulido H, Kuo DY, Howard T, Qualls CR, Lee SJ, Verschraegen CF, Hathaway HJ, Joste NE, Prossnitz ER. GPR30 predicts poor survival for ovarian cancer. Gynecol Oncol. 2009; 114: 465-471.

39. Vivacqua A, De Marco P, Santolla MF, Cirillo F, Pellegrino M, Panno ML, Abonante S, Maggiolini M. Estrogenic gper signalling regulates mir144 expression in cancer cells and cancer-associated fibroblasts (cafs). Oncotarget. 2015; 6:16573-87. doi: 10.18632/oncotarget.4117.

40. De Marco P, Cirillo F, Vivacqua A, Malaguarnera R, Belfiore A, Maggiolini M. Novel Aspects Concerning the 
Functional Cross-Talk between the Insulin/IGF-I System and Estrogen Signalling in Cancer Cells. Front Endocrinol (Lausanne). 2015; 6: 30. doi: 10.3389/fendo.2015.00030.

41. Lappano R, Pisano A, Maggiolini M. GPER Function in Breast Cancer: An Overview. Front Endocrinol (Lausanne). 2014; 5: 66. doi: 10.3389/fendo.2014.00066.

42. Santolla MF, De Francesco EM, Lappano R, Rosano C, Abonante S, Maggiolini M. Niacin activates the $G$ protein estrogen receptor (GPER)-mediated signalling. Cell Signal. 2014; 7: 1466-1475.

43. Santolla MF, Lappano R, De Marco P, Pupo M, Vivacqua A, Sisci D, Abonante S, Iacopetta D, Cappello AR, Dolce V, Maggiolini M. G protein-coupled estrogen receptor mediates the up-regulation of fatty acid synthase induced by $17 \beta$-estradiol in cancer cells and cancer-associated fibroblasts. J Biol Chem. 2012; 287: 43234-43245.

44. De Francesco EM, Angelone T, Pasqua T, Pupo M, Cerra MC, Maggiolini M. GPER mediates cardiotropic effects in spontaneously hypertensive rat hearts. PLoS One. 2013; 8: e69322.

45. Pupo M, Pisano A, Lappano R, Santolla MF, De Francesco EM, Abonante S, Rosano C, Maggiolini M. Bisphenol A induces gene expression changes and proliferative effects through GPER in breast cancer cells and cancer-associated fibroblasts. Environ Health Perspect. 2012; 120: 1177-1182.

46. Filice E, Angelone T, De Francesco EM, Pellegrino D, Maggiolini M, Cerra MC. Crucial role of phospholamban phosphorylation and S-nitrosylation in the negative lusitropism induced by $17 \beta$-estradiol in the male rat heart. Cell Physiol Biochem. 2011; 28: 41-52.

47. Lappano R, Rosano C, De Marco P, De Francesco EM, Pezzi V, Maggiolini M. Estriol acts as a GPR30 antagonist in estrogen receptor-negative breast cancer cells. Mol Cell Endocrinol. 2010; 320: 162-170.

48. Lappano R, Santolla MF, Pupo M, Sinicropi MS, Caruso A, Rosano C, Maggiolini M. MIBE acts as antagonist ligand of both estrogen receptor $\alpha$ and GPER in breast cancer cells. Breast Cancer Res. 2012; 14: R12.

49. Maggiolini M, Santolla MF, Avino S, Aiello F, Rosano C, Garofalo A, Grande F. Identification of two benzopyrroloxazines acting as selective GPER antagonists in breast cancer cells and cancer-associated fibroblasts. Future Med Chem. 2015; 7: 437-448.

50. Sinicropi MS, Lappano R, Caruso A, Santolla MF, Pisano A, Rosano C, Capasso A, Panno A, Lancelot JC, Rault S, Saturnino C, Maggiolini M. (6-bromo-1,4-dimethyl-9Hcarbazol-3-yl-methylene)-hydrazine (carbhydraz) acts as a GPER agonist in breast cancer cells. Curr Top Med Chem. 2015; 15: 1035-42.

51. Bartella V, De Marco P, Malaguarnera R, Belfiore A, Maggiolini M. New advances on the functional cross-talk between insulin-like growth factor-I and estrogen signalling in cancer. Cell Signal. 2012; 24 : 1515-1521.

52. De Marco P, Bartella V, Vivacqua A, Lappano R, Santolla
MF, Morcavallo A, Pezzi V, Belfiore A, Maggiolini M. Insulin-like growth factor-I regulates GPER expression and function in cancer cells. Oncogene. 2013; 32 :678-688.

53. De Marco P, Romeo E, Vivacqua A, Malaguarnera R, Abonante S, Romeo F, Pezzi V, Belfiore A, Maggiolini M. GPER1 is regulated by insulin in cancer cells and cancerassociated fibroblasts. Endocr Relat Cancer. 2014; 21: 739753.

54. Santolla MF, Avino S, Pellegrino M, De Francesco EM, De Marco P, Lappano R, Vivacqua A, Cirillo F, Rigiracciolo DC, Scarpelli A, Abonante S and Maggiolini M. SIRT1 is involved in oncogenic signaling mediated by GPER in breast cancer. Cell Death and Disease. 2015 Cdx.doi. org/10.1038/cddis.2015.201.

55. Lappano R, Rosano C, Pisano A, Santolla MF, De Francesco EM, De Marco P, Dolce V, Ponassi M, Felli L, Cafeo G, Kohnke FH, Abonante S, Maggiolini M. A calixpyrrole derivative acts as a GPER antagonist: mechanisms and models. Dis Model Mech. 2015; pii: dmm.021071.

56. Albanito L, Lappano R, Madeo A, Chimento A, Prossnitz ER, Cappello AR, Dolce V, Abonante S, Pezzi V, Maggiolini M. Effects of Atrazine on Estrogen Receptor $\alpha$ - and G Protein-Coupled Receptor 30-Mediated Signalling and Proliferation in Cancer Cells and Cancer-Associated Fibroblasts. Environ Health Perspect. 2015; 123: 493-499.

57. Vivacqua A, Romeo E, De Marco P, De Francesco EM, Abonante S, Maggiolini M. GPER mediates the Egr-1 expression induced by $17 \beta$-estradiol and 4-hydroxitamoxifen in breast and endometrial cancer cells. Breast Cancer Res Treat. 2012; 133: 1025-1035.

58. Lappano R, Rosano C, Santolla MF, Pupo M, De Francesco EM, De Marco P, Ponassi M, Spallarossa A, Ranise A, Maggiolini M. Two novel GPER agonists induce gene expression changes and growth effects in cancer cells. Curr Cancer Drug Targets. 2012; 12: 531-542.

59. Lappano R, Maggiolini M. G protein-coupled receptors: novel targets for drug discovery in cancer. Nat Rev Drug Discov. 2011; 10: 47-60.

60. Lappano R, Maggiolini M. GPCRs and cancer. Acta Pharmacol Sin. 2012; 33: 351-362.

61. Madeo A, Maggiolini M. Nuclear alternate estrogen receptor GPR30 mediates 17beta-estradiol-induced gene expression and migration in breast cancer-associated fibroblasts. Cancer Res. 2010; 70: 6036-6046. doi: 10.1158/0008-5472.CAN-10-0408.

62. Pupo M, Pisano A, Abonante S, Maggiolini M, Musti AM. GPER activates Notch signalling in breast cancer cells and cancer-associated fibroblasts (CAFs). Int J Biochem Cell Biol. 2014; 46: 56-67.

63. Pupo M, Vivacqua A, Perrotta I, Pisano A, Aquila S, Abonante S, Gasperi-Campani A, Pezzi V, Maggiolini M. The nuclear localization signal is required for nuclear GPER translocation and function in breast Cancer-Associated Fibroblasts (CAFs). Mol Cell Endocrinol. 2013; 376: 23-32. 
64. Martinez-Outschoorn UE, Lisanti MP, Sotgia F. Semin Cancer Biol. Catabolic cancer-associated fibroblasts transfer energy and biomass to anabolic cancer cells, fueling tumor growth. 2014; 25: 47-60.

65. Martinez-Outschoorn U, Sotgia F, Lisanti MP. Tumor microenvironment and metabolic synergy in breast cancers: critical importance of mitochondrial fuels and function. Semin Oncol. 2014; 41: 195-216.

66. Sotgia F, Martinez-Outschoorn UE, Lisanti MP. Cancer metabolism: new validated targets for drug discovery. Oncotarget. 2013; 4: 1309-1316.

67. Yu X, Filardo EJ, Shaikh ZA. The membrane estrogen receptor GPR30 mediates cadmium-induced proliferation of breast cancer cells. Toxicol Appl Pharmacol. 2010; 245: 83-90.

68. Albanito L, Sisci D, Aquila S, Brunelli E, Vivacqua A, Madeo A, Lappano R, Pandey DP, Picard D, Mauro L, Andò S, Maggiolini M. Epidermal growth factor induces $\mathrm{G}$ protein-coupled receptor 30 expression in estrogen receptornegative breast cancer. Endocrinology. 2008; 149: 37993808 . 